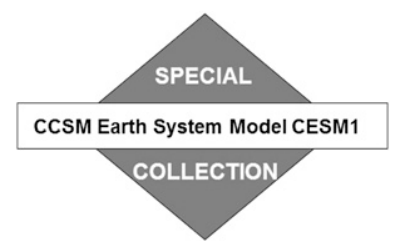

\title{
Twentieth-Century Oceanic Carbon Uptake and Storage in CESM1(BGC)*
}

\author{
Matthew C. Long, Keith Lindsay, and Synte Peacock \\ Climate and Global Dynamics Division, National Center for Atmospheric Research, ${ }^{+}$Boulder, Colorado \\ J. KeITH MOORE \\ Earth System Science, University of California, Irvine, Irvine, California \\ SCOTT C. DONEY \\ Marine Chemistry and Geochemistry, Woods Hole Oceanographic Institution, Woods Hole, Massachusetts
}

(Manuscript received 4 April 2012, in final form 11 March 2013)

\begin{abstract}
Ocean carbon uptake and storage simulated by the Community Earth System Model, version 1Biogeochemistry [CESM1(BGC)], is described and compared to observations. Fully coupled and ocean-ice configurations are examined; both capture many aspects of the spatial structure and seasonality of surface carbon fields. Nearly ubiquitous negative biases in surface alkalinity result from the prescribed carbonate dissolution profile. The modeled sea-air $\mathrm{CO}_{2}$ fluxes match observationally based estimates over much of the ocean; significant deviations appear in the Southern Ocean. Surface ocean $p \mathrm{CO}_{2}$ is biased high in the subantarctic and low in the sea ice zone. Formation of the water masses dominating anthropogenic $\mathrm{CO}_{2}\left(\mathrm{C}_{\mathrm{ant}}\right)$ uptake in the Southern Hemisphere is weak in the model, leading to significant negative biases in $\mathrm{C}_{\text {ant }}$ and chlorofluorocarbon (CFC) storage at intermediate depths. Column inventories of $\mathrm{C}_{\text {ant }}$ appear too high, by contrast, in the North Atlantic. In spite of the positive bias, this marks an improvement over prior versions of the model, which underestimated North Atlantic uptake. The change in behavior is attributable to a new parameterization of density-driven overflows. CESM1(BGC) provides a relatively robust representation of the ocean-carbon cycle response to climate variability. Statistical metrics of modeled interannual variability in sea-air $\mathrm{CO}_{2}$ fluxes compare reasonably well to observationally based estimates. The carbon cycle response to key modes of climate variability is basically similar in the coupled and forced ocean-ice models; however, the two differ in regional detail and in the strength of teleconnections.
\end{abstract}

\section{Introduction}

Over the last 200 years the ocean has absorbed $118 \pm$ $19 \mathrm{Pg}$ carbon $\left(1 \mathrm{Pg}=10^{15} \mathrm{~g}\right)$, an amount equivalent to $25 \%-30 \%$ of the total $\mathrm{CO}_{2}$ emitted by fossil-fuel burning, cement production, and land-use change over this

\footnotetext{
* Supplemental information related to this paper is available at the Journals Online website: http://dx.doi.org/10.1175/JCLI-D-1200184.s1.

+ The National Center for Atmospheric Research is sponsored by the National Science Foundation.
}

Corresponding author address: Matthew C. Long, National Center for Atmospheric Research, 1850 Table Mesa Drive, Boulder, CO 80305.

E-mail: mclong@ucar.edu period (Sabine et al. 2004; Le Quéré et al. 2009). The ocean carbon sink has partially mitigated $\mathrm{CO}_{2}$-induced warming by slowing the rise of atmospheric $\mathrm{CO}_{2}$ during the anthropocene (Crutzen 2006). However, the mechanisms regulating the ocean carbon sink are sensitive to climate change; thus, uncertainty in future climatecarbon cycle interactions leads to large uncertainty in the future efficiency of the ocean carbon sink (Friedlingstein et al. 2006; Fung et al. 2005). Given strong potential for climate-carbon feedback, accurate and mechanistic representation of oceanic carbon uptake and storage is essential to robust climate prediction.

The recent Coupled Carbon Cycle Climate Model Intercomparison Project $\left(\mathrm{C}^{4} \mathrm{MIP}\right)$ compared different models with interactive carbon cycle representations. While all the $\mathrm{C}^{4} \mathrm{MIP}$ models agreed that climate warming will reduce the ocean carbon sink, the magnitude of the 
ocean sink's sensitivity to climate varied widely among the models (Friedlingstein et al. 2006). Our ability to distinguish among disparate model estimates of climatecarbon feedbacks will rely on assessment of the relative skill of the respective ocean-carbon cycle representations.

The objective of this paper is to introduce and evaluate the ocean-carbon cycle representation in the Community Earth System Model, version 1-Biogeochemistry [CESM1 (BGC)]. Ocean carbon biogeochemistry in CESM1(BGC) is represented by the Biogeochemical Elemental Cycle (BEC) model, which has been extensively applied in the Community Climate System Model (the forerunner of CESM) framework (e.g., Moore et al. 2004; Doney et al. 2009a). CESM1 marks the first public release of the BEC model. We compare CESM1's ocean-carbon cycle in twentieth-century integrations to available observational data. Two configurations of CESM1 are considered: 1) the fully coupled Earth system model, including ocean, sea ice, land, and atmosphere models; and 2) the ocean-ice component models forced by atmospheric reanalysis data. Our analysis is aimed at identifying model biases and examining the model's twentieth-century mean state, seasonal cycle, interannual variability, and transient response. Furthermore, we explicitly test the degree to which the fully coupled model is able to represent observed atmosphere-driven variability as captured in the forced ocean-ice model. The ocean-carbon cycle response in the twenty-first century is considered in a separate paper (Long et al. 2013, manuscript submitted to J. Climate).

\section{Numerical model}

\section{a. Model description}

The Community Earth System Model is an extension of the Community Climate System Model, version 4 (CCSM4). CCSM4 is a fully coupled global climate model consisting of land, atmosphere, ocean, and sea ice components (Gent et al. 2011). CESM1(BGC) is distinguished from CCSM4 by the optional inclusion of a land-ice model, the option to use different atmospheric models, and a comprehensive global carbon cycle, including an ocean biogeochemistry module.

The physical and land surface components of the coupled model used in this paper are identical to the CCSM4 configuration discussed in Gent et al. (2011), with the exception that the depth profile of shortwave absorption in the ocean is computed using prognostic chlorophyll fields, rather than a fixed satellite-derived monthly climatology. This change has relatively little impact on the simulated climate (Lindsay et al. 2012, manuscript submitted to J. Climate). The atmosphere model used is the Community Atmosphere Model, version 4 (CAM4;
Neale et al. 2013) and the dynamic land-ice component is not active. CAM4 has a horizontal resolution of $1.25^{\circ} \times 0.9^{\circ}$ and 26 vertical layers (Neale et al. 2013). The Community Land Model, version 4 (CLM4), operates on the same horizontal grid as CAM4 (Lawrence et al. 2012). The ocean component of CESM1 is based on the Parallel Ocean Program, version 2 (POP2; Smith et al. 2010), a $z$-level hydrostatic primitive equation model. Danabasoglu et al. (2012) provide detailed descriptions of the various physical, numerical, and software developments included in the latest CESM ocean component and also present an analysis of model biases and physical dynamics; we make specific reference to their work throughout this paper, where the reader may find additional details relevant to the ocean biogeochemistry simulation. The CESM1 sea ice component is the Community Ice Code, version 4 (CICE4). CICE4 operates on the ocean horizontal grid; it represents a subgrid-scale ice thickness distribution and elasticviscous-plastic rheology (Hunke and Lipscomb 2008).

In the simulations presented here, the CESM ocean component is integrated with a nominal horizontal resolution of $1^{\circ} \times 1^{\circ}$ and 60 vertical levels. The horizontal grid has enhanced resolution in the tropics and high latitudes; the Northern Hemisphere pole is displaced, residing over Greenland. The vertical grid spacing is $10 \mathrm{~m}$ in the upper $160 \mathrm{~m}$ and varies with depth below, increasing to $250 \mathrm{~m}$ by a depth of $\sim 3500 \mathrm{~m}$, then remaining constant to the model bottom at $5500 \mathrm{~m}$. Physical transport terms are partitioned into resolved and unresolved components. Mesoscale eddy transport is parameterized according to Gent and McWilliams (1990; GM). The eddy-induced advection coefficient varies in space and time according to Danabasoglu and Marshall (2007). A variable coefficient provides a better representation of changes in eddy activity resulting from variable surface momentum forcing than a constant value; this is a key feature, allowing the model to more realistically capture the circulation response to changing winds, particularly in the Southern Ocean (Danabasoglu and Marshall 2007; Gent and Danabasoglu 2011; Gent 2011; Farneti and Gent 2011). Boundary layer dynamics are represented using the $K$-profile parameterization (KPP) of Large et al. (1994), with a latitudinally varying background internal wave diffusivity (Danabasoglu et al. 2012). The background diffusivities do not have depth dependence, rather abyssal tidal mixing is considered separately (Danabasoglu et al. 2012). Mixed layer restratification by submesoscale eddies is parameterized using the method of Fox-Kemper et al. (2010). Densitydriven overflows through the Denmark Strait, Faroe Bank Channel, and the Ross and Weddell Seas' continental shelves are represented by an explicit parameterization (Danabasoglu et al. 2010, 2012). 
Ocean carbon biogeochemistry in CESM1(BGC) is represented by the ocean Biogeochemical Elemental Cycle model embedded within the CESM ocean component. The BEC model has been described in a number of earlier papers (see Moore et al. 2004; Doney et al. 2006) and has been implemented within CESM1 with limited modification.

The surface ocean ecosystem comprises important sources and sinks for carbon. The BEC ecosystem model is built on the classical nutrient-phytoplanktonzooplankton-detritus food web model. There are three phytoplankton functional types (PFT; diatoms, "small" pico-nano phytoplankton, and diazotrophs) and one zooplankton class with PFT-specific grazing rates. Phytoplankton growth is determined as a function of temperature, multinutrient $(\mathrm{N}, \mathrm{P}, \mathrm{Si}$, and $\mathrm{Fe})$ limitation, and light availability. Carbon export and remineralization is parameterized after Armstrong et al. (2002), who specify separate remineralization length scales for mineralballast associated particulate organic material (POM) and purely soft tissue POM, the latter remineralizing at shallower depths. Seafloor sediment processes and storage are not represented in the model; material reaching the bottom ocean layer is remineralized in a single time step. The model solves the full nonlinear seawater carbonate system (i.e., $p \mathrm{H}, p \mathrm{CO}_{2}$, and bicarbonate and carbonate ion concentrations) diagnostically, as a function of prognostic dissolved inorganic carbon (DIC), alkalinity, and temperatureand salinity-dependent equilibrium coefficients (Dickson and Goyet 1994). Alkalinity is modified by the consumption and remineralization of nitrate (and ammonium), as well as biogenic calcification and dissolution of $\mathrm{CaCO}_{3}$ (Najjar and Orr 1998). Biogenic calcification is modeled as proportional to a temperature-dependent fraction of small phytoplankton production; an exponential curve is prescribed to model dissolution of sinking $\mathrm{CaCO}_{3}$ (Moore et al. 2002, 2004). There is no dependence of calcification-dissolution rates on saturation state. Riverine inputs into the model ocean carry no dissolved tracers and thus only contribute to the freshwater balance.

\section{b. Model experiments}

Table 1 provides a list of the numerical experiments examined in this article. Configurations denoted as "coupled" involved the CESM1(BGC) fully coupled system (i.e., atmosphere, land, ocean, and sea ice). In the ocean-ice integrations, the ocean and ice component models are forced by atmospheric observations and reanalyses, following the Coordinated Ocean-Ice Reference Experiments (CORE; Griffies et al. 2009) protocol. In these, the ocean-ice model is forced with sea-air
TABLE 1. List of numerical experiments. Obs. = observations.

\begin{tabular}{lcccc}
\hline \hline \multicolumn{1}{c}{ Label } & Configuration & $\begin{array}{c}\mathrm{BGC}- \\
\mathrm{CO}_{2}{ }^{*}\end{array}$ & $\begin{array}{c}\text { Radiative- } \\
\mathrm{CO}_{2} * *\end{array}$ & Years \\
\hline CPLD1850 & Coupled & 284.7 & Obs. & $1850-2005$ \\
CPLD20C & Coupled & Obs. & Obs. & $1850-2005$ \\
CORE1850 & Ocean-ice & 284.7 & Obs. & $1850-2005$ \\
CORE20C & Ocean-ice & Obs. & Obs. & $1850-2007$
\end{tabular}

* $\mathrm{CO}_{2}$ used as boundary condition for BGC surface fluxes.

** $\mathrm{CO}_{2}$ concentration used in radiative transfer calculation.

fluxes of heat, freshwater, and momentum derived using a methodology (Large and Yeager 2009) combining 6-h surface wind, temperature, specific humidity, and density from the National Centers for Environmental Prediction (NCEP) reanalysis (Kalnay et al. 1996) with satellitebased radiation, sea surface temperature, and precipitation products.

Biogeochemical fields were initialized using databased climatologies; for instance, DIC was from the Global Ocean Data Analysis Project (GLODAP; Key et al. 2004) and nutrients were from the World Ocean Atlas (WOA; Garcia et al. 2006). Subsequently, the fully coupled model was integrated for a period of $1000 \mathrm{yr}$ to allow the deep ocean to approach equilibrium; the tracer fields resulting from this spinup procedure were used to initialize a 1000 -yr steady-state climate simulation (Lindsay et al. 2012, manuscript submitted to J. Climate), in which atmospheric $\mathrm{CO}_{2}$ was held constant at preindustrial levels $\left(p \mathrm{CO}_{2}^{\mathrm{atm}}=284.7 \mathrm{ppm}\right)$. In this paper, we examine two "twentieth century" simulations branched off this steady-state run after 150 years of integration.

There are multiple atmospheric $\mathrm{CO}_{2}$ tracers in CESM1 (BGC): radiative $\mathrm{CO}_{2}\left(\mathrm{rad}-\mathrm{CO}_{2}\right)$ and the $\mathrm{CO}_{2}$ concentration seen as a boundary condition by the ocean and land biogeochemistry modules (BGC- $\mathrm{CO}_{2}$ ) can be distinct quantities. To define a coupled control run (CPLD1850), we specify rad- $\mathrm{CO}_{2}$ according to the instrumental record but hold $\mathrm{BGC}-\mathrm{CO}_{2}$ constant at the 1850 level. In the coupled transient run (CPLD20C), both $\mathrm{CO}_{2}$ tracers (rad- $\mathrm{CO}_{2}$ and $\mathrm{BGC}-\mathrm{CO}_{2}$ ) are identical and specified according to the observational record. While CESM1 (BGC) has the capability to model atmospheric $\mathrm{CO}_{2}$ as a spatially explicit prognostic tracer responsive to $\mathrm{CO}_{2}$ exchange with the ocean and terrestrial biosphere (Lindsay et al. 2012, manuscript submitted to J. Climate), in the experiments presented here $p \mathrm{CO}_{2}^{\mathrm{atm}}$ has been specified as a globally uniform but annually evolving field with no seasonal cycle. The land surface model is active in the coupled integrations; however, its impact on the solution is negligible, since with prescribed $p \mathrm{CO}_{2}^{\mathrm{atm}}$ there is no direct land-ocean communication 
through the atmospheric carbon reservoir. Biogeophysical feedbacks induced by elevated $p \mathrm{CO}_{2}^{\text {atm }}$ (i.e., "greening of the land model") are very small over the twentieth century.

The initialization procedure was different for the CORE-forced runs. In these, the control simulation (CORE1850) biogeochemical fields were initialized to observed climatologies, while the physical state was taken from a CCSM4 ocean-ice hindcast run that included weak (4-yr time scale) salinity restoring to observations in the upper $50 \mathrm{~m}$ (Danabasoglu et al. 2012). The CORE dataset covers the period 1948-2007 (60 yr); these modern observations were used for both spinup and the twentieth-century simulation. The model was run for four repeating 60-yr forcing cycles (model years 1-240). Physical fields and dynamic tracers (temperature and salinity) were reset to their initial values (those from the previous hindcast simulation, not observations) at the beginning of each cycle. This strategy was applied to mitigate the impact of drift in the physical solution. The transient simulation (CORE20C) was branched off of CORE1850 at model year 83; thus, model years 83240 correspond to years $1850-2007$. However, it is only during the last $60 \mathrm{yr}$ of the CORE-forced integrations (1948-2007; model years 181-240) that the forcing data are aligned with the time period they actually represent. Recycling the forcing data results in discontinuities where one 60-yr period ends and another begins; at these transitions, the forcing year 2007 precedes forcing year 1948 (at model year 180-181, for instance). This discontinuity shocks the system and introduces spurious flux variability (particularly in the equatorial Pacific); thus, we restrict our analysis of interannual variability of this integration to after year 1960. Further discussion of this spinup methodology and repeat forcing cycles can be found in Doney et al. (2007).

One minor difference between CPLD20C and CORE20C is that the coupled integration includes timevarying nitrogen deposition, ramping during the twentieth century (Lamarque et al. 2010), while the ocean-ice hindcast has constant nitrogen deposition; this has little impact on global-scale ocean fluxes (Krishnamurthy et al. 2007, 2009).

\section{c. Model analysis}

Oceanic DIC in the twentieth-century integrations can be divided into two components: natural and anthropogenic. Natural $\mathrm{CO}_{2}\left(\mathrm{C}_{\mathrm{nat}}\right)$ is the component of ocean carbon in approximate steady-state balance with the preindustrial atmosphere. Anthropogenic $\mathrm{CO}_{2}\left(\mathrm{C}_{\mathrm{ant}}\right)$ is the additional carbon absorbed by the ocean because of the atmospheric $\mathrm{CO}_{2}$ transient. We compute fluxes and inventories of $\mathrm{C}_{\text {ant }}$ by subtracting simulated fields in the control integrations (CORE1850 and CPLD1850) from those in the respective transient integrations (CORE20C and CPLD20C). The control integrations include twentieth-century climate change (see above); thus, the climate effects on $\mathrm{C}_{\text {nat }}$ distributions are present in both control and transient integrations and cancel in subtraction. Interannual variability in the natural carbon cycle complicates this approach somewhat. For the CORE-forced runs, physical dynamics driving carbon cycle variability are bit-for-bit identical in the control and transient simulations. Variability in each coupled model integration, however, evolves independently. To avoid introducing excessive variance into $C_{a n t}$ estimates, we compute 11-yr running means of fields in the control simulations and use these to define $\mathrm{C}_{\mathrm{nat}}$; for consistency, we use this approach for both CORE-forced and coupled integrations.

Deep-ocean drift is a separate, but related, issue involved with model analysis. Over the 156-yr integration corresponding to the twentieth century, the global ocean in CPLD1850 lost about $4 \mathrm{PgC}$, indicating the persistence of weak deep-ocean drift even after $>1000 \mathrm{yr}$ of spinup. Drift was not spatially homogenous but rather distributed differently in each ocean basin-similar to the model drifts in potential temperature and salinity documented by Danabasoglu et al. (2012). In the COREforced integration, shorter spinup resulted in larger model drift: globally the ocean gained about $12 \mathrm{PgC}$ in CORE1850, distributed somewhat differently than in the coupled model, with significant accumulation of DIC in the eastern part of basins in tropical regions. The impact of model drift on estimates of the $\mathrm{C}_{\mathrm{ant}}$ perturbation is relatively small since comparable drift occurs in both control and transient integrations and is therefore linearly corrected by subtraction.

To separate biases related to freshwater inventories from those associated with the carbon cycle representation, we make use of salinity-normalized quantities. These we denote with a small $s$ (i.e., $s \mathrm{DIC}=\mathrm{DIC} \times \bar{S} / S$, where $\bar{S}=35$; Sarmiento and Gruber 2006). This approach removes much of the variability in DIC and alkalinity fields associated with the concentrating (diluting) freshwater fluxes of evaporation (precipitation) or ice formation (melt; Doney et al. 2009a).

In considering biases in surface variables that affect ocean $\mathrm{CO}_{2}$ uptake, we make use of "equilibrium DIC" $\left(\mathrm{DIC}_{\mathrm{eq}}\right)$, which is the DIC concentration of seawater at equilibrium with $p \mathrm{CO}_{2}^{\mathrm{atm}}$. For a given value of $p \mathrm{CO}_{2}^{\mathrm{atm}}$, we compute $\mathrm{DIC}_{\mathrm{eq}}$ from surface temperature, salinity, phosphate, silicate, and alkalinity, using published thermodynamic relationships (Dickson and Goyet 1994). To investigate the effect of biases in temperature and alkalinity on $\mathrm{DIC}_{\mathrm{eq}}$, we compute $\mathrm{DIC}_{\mathrm{eq}}$ using data 
from observational climatologies but replace the observed field of interest with the modeled field.

To investigate climate-driven variability in carbon cycle dynamics, we compute monthly anomalies of related fields as $Y^{\prime}=Y-\bar{Y}_{\text {mon }}$, where $\bar{Y}_{\text {mon }}$ is the monthly climatology of field $Y$ and the prime denotes the anomaly. Following Doney et al. (2009a), we construct linear Taylor series expansions of the monthly anomalies at each grid point in terms of anomalies in the driving mechanisms $X^{\prime}$ :

$$
Y^{\prime} \approx \sum_{i} \frac{\partial Y}{\partial X_{i}} X_{i}^{\prime}+\mathcal{O}\left(X_{i}^{\prime 2}, X_{i}^{\prime} X_{j}^{\prime}\right)
$$

Sea-air exchange of $\mathrm{CO}_{2}$ is computed as

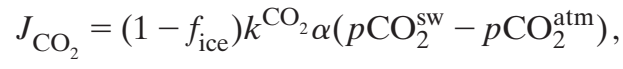

where $f_{\text {ice }}$ is the fraction of the sea surface covered by ice, $\alpha$ is the temperature- and salinity-dependent $\mathrm{CO}_{2}$ solubility (Weiss 1974), and $k^{\mathrm{CO}_{2}}$ is the gas transfer velocity, calculated as a quadratic function of wind speed as well as the temperature-dependent Schmidt number (Wanninkhof 1992). The terms $p \mathrm{CO}_{2}^{\mathrm{sw}}$ and $p \mathrm{CO}_{2}^{\mathrm{atm}}$ are the partial pressure of $\mathrm{CO}_{2}$ in the surface ocean and atmosphere, respectively.

To examine mechanisms driving monthly anomalies of sea-air $\mathrm{CO}_{2}$ flux [Eq. (2)], a decomposition similar to (1) can be applied:

$$
J_{\mathrm{CO}_{2}}^{\prime}=\underbrace{(k \alpha)^{\prime} \overline{\Delta p \mathrm{CO}_{2}}}_{\mathrm{I}}+\underbrace{\overline{(k \alpha)} \Delta p \mathrm{CO}_{2}^{\prime}}_{\mathrm{II}}+\underbrace{\left[(k \alpha)^{\prime} \Delta p \mathrm{CO}_{2}^{\prime}-\overline{(k \alpha)^{\prime} \Delta p \mathrm{CO}_{2}^{\prime}}\right]}_{\text {III }},
$$

where the right-hand side terms represent the contribution to sea-air flux variability from variation in ice cover and the gas transfer velocity [term I; $k=\left(1-f_{\text {ice }}\right) k^{\mathrm{CO}_{2}}$, Eq. (2)], $\Delta p \mathrm{CO}_{2}$ anomalies (term II), and the cross term corrected for the mean of the cross-term anomalies (term III). Our analysis of model results indicates that the cross terms contribute little to the variability in $J_{\mathrm{CO}_{2}}^{\prime}$, which is consistent with the findings of Doney et al. (2009a); we therefore focus on contributions from terms I and II. The piston velocity formulation includes temperature dependence, through its dependence on the Schmidt number. Temperature-induced variability in $k$ and $\alpha$ approximately cancel; therefore, term I predominately reflects fluctuations in wind speed, with an additional contribution from variability in fractional ice cover (Doney et al. 2009a).

A similar linear decomposition can be applied to monthly $p \mathrm{CO}_{2}^{\mathrm{sw}}$ anomalies:

$$
\begin{aligned}
p \mathrm{CO}_{2}^{\prime} \approx & \frac{\partial p \mathrm{CO}_{2}}{\partial T} T^{\prime}+\frac{\partial p \mathrm{CO}_{2}}{\partial S} S^{\prime}+\frac{\partial p \mathrm{CO}_{2}}{\partial \mathrm{fw}} \mathrm{fw}^{\prime} \\
& +\frac{S}{\bar{S}} \frac{\partial p \mathrm{CO}_{2}}{\partial \mathrm{DIC}} s \mathrm{DIC}^{\prime}+\frac{S}{\bar{S}} \frac{\partial p \mathrm{CO}_{2}}{\partial \mathrm{Alk}_{\mathrm{k}}} s \mathrm{Alk}^{\prime},
\end{aligned}
$$

where the terms on the right-hand side represent, respectively, the effect of variability in sea surface temperature, salinity (solubility), concentrating-diluting freshwater effects (fw) (see Lovenduski et al. 2007), salinity-normalized DIC, and alkalinity (Alk) (Doney et al. 2009a).

Much of the variability in $p \mathrm{CO}_{2}^{\mathrm{sw}}$ is driven by changes in surface DIC, for which we use the upper ocean $(0-100 \mathrm{~m})$
DIC inventory as a proxy. Monthly anomalies of the DIC inventory can be partitioned as follows:

$$
\int_{0}^{100}\left(\frac{\partial \mathrm{DIC}}{\partial t}\right) d z=J_{\mathrm{CO}_{2}}^{\prime}+J_{\text {virtual }}^{\prime}+J_{\text {bio }}^{\prime}+J_{\text {phy }}^{\prime}
$$

where $J_{\mathrm{CO}_{2}}$ is the air-sea $\mathrm{CO}_{2}$ flux, $J_{\text {virtual }}$ is the virtual flux of DIC in the volume conserving model due to freshwater exchange, $J_{\text {bio }}$ is the vertically integrated net biological effect on DIC (i.e., net community production), and $J_{\text {phy }}$ is the vertically integrated net physical transport of DIC into the top $100 \mathrm{~m}$ due to advection and mixing (in this case, including both resolved and unresolved processes).

To characterize the mechanisms driving the response to climate variability, we compute indices characterizing three dominant modes of climate variability: El NiñoSouthern Oscillation (ENSO; Trenberth 1997), the southern annular mode (SAM; Thompson and Solomon 2002), and the North Atlantic Oscillation (NAO; Hurrell 1995). We then regress the biogeochemical anomalies $\left(Y^{\prime}\right)$ and anomaly components $\left[(\partial Y / \partial X) X_{i}^{\prime}\right]$ onto the climate indices $\left(\Psi_{j}\right)$ at each grid point,

$$
\frac{\partial Y}{\partial X_{i}} X_{i}^{\prime}=\beta_{i j} \Psi_{j}
$$

using linear least squares regression to estimate $\beta_{i j}$. We take the $\beta_{i j}$ to represent the effect of climate-driven variability in $X_{i}$ on the anomalies $Y^{\prime}$. So as to facilitate comparison of patterns across each of the modes, we standardize each climate index by dividing by its standard 
deviation. All metrics of significance presented are relative to the $95 \%$ level. We take autocorrelation into account in computing significance by reducing degrees of freedom (DF) according to DF $=N \times\left(1-r_{1}\right) /\left(1+r_{1}\right)$, where $N$ is the original sample size and $r_{1}$ is the lag-one autocorrelation (Zwiers and von Storch 1995).

In the examination of multidecadal trends in $p \mathrm{CO}_{2}$, we use the approach of Takahashi et al. (2002) to separate trend components driven by changes in temperature from those related to increasing DIC and equilibrium effects, such as changes in alkalinity.

\section{Observational datasets}

Modeled surface ocean $p \mathrm{CO}_{2}$ and sea-air fluxes are compared to those of Takahashi et al. (2009). Globalscale sea-air $\mathrm{CO}_{2}$ fluxes are not observed directly; rather, Takahashi et al. (2009) combine observations of the sea-air $p \mathrm{CO}_{2}$ difference $\left(\Delta p \mathrm{CO}_{2}\right)$ with bulk gas exchange parameterizations driven by wind speed data (reanalyses) to estimate sea-air $\mathrm{CO}_{2}$ fluxes (e.g., Takahashi et al. 1997, 2002, 2009). The Takahashi et al. (2009) climatology is available at a monthly resolution on a $4^{\circ} \times 5^{\circ}$ grid and is produced for the reference year 2000. When comparing model output to Takahashi et al. (2009), we use 11-yr averages centered on 2000. We also make use of the $\Delta p \mathrm{CO}_{2}$-based flux estimates of Park et al. (2010). Park et al. (2010) use empirical relationships to estimate $\Delta p \mathrm{CO}_{2}$ from SST fields; combined with wind speed, these data characterize interannual variability in sea-air $\mathrm{CO}_{2}$ fluxes at a monthly resolution for the period 1990-2009 on the same grid as Takahashi et al. (2009), excluding sea ice affected regions south of $60^{\circ} \mathrm{S}$, the Arctic Ocean, and coastal-marginal seas.

Model $p \mathrm{CO}_{2}^{\mathrm{sw}}$ is output as $p \mathrm{CO}_{2}$ in dry air $\left(p \mathrm{CO}_{2, \mathrm{dry}}^{\mathrm{sw}}\right)$, whereas observational $p \mathrm{CO}_{2}^{\mathrm{sw}}$ datasets are provided as values at $100 \%$ humidity $\left(p \mathrm{CO}_{2 \text {,wet }}^{\mathrm{sw}}\right)$. To convert the modeled $p \mathrm{CO}_{2}^{\mathrm{sw}}$ to wet values we use

$$
p \mathrm{CO}_{2, \mathrm{wet}}^{\mathrm{sw}}=p \mathrm{CO}_{2, \mathrm{dry}}^{\mathrm{sw}}\left(\frac{P}{P-p \mathrm{H}_{2} \mathrm{O}}\right),
$$

where $P$ is the ambient atmospheric pressure (atm) and $p \mathrm{H}_{2} \mathrm{O}$ is determined as a function of sea surface temperature and salinity according to Weiss and Price [1980, their Eq. (10)].

Observationally based alkalinity, dissolved inorganic carbon, and chlorofluorocarbon distributions are taken from the GLODAP database (Key et al. 2004). The data that make up GLODAP were collected over the 1990s; thus, when comparing model output to these data, we use 11-yr averages centered on 1995-this approach is used to diminish the impact of interannual variability on comparisons. GLODAP climatologies are available on a $1^{\circ} \times 1^{\circ}$ horizontal grid with 33 vertical levels, which we interpolate to the model grid. GLODAP reports constituent concentrations per mass of seawater. Since the CESM ocean component is volume conserving, we convert observation-based concentrations to per-volume units using a constant reference density, $\rho_{0}=1026 \mathrm{~kg} \mathrm{~m}^{-3}$. Anthropogenic $\mathrm{CO}_{2}$ concentration estimates included in GLODAP are based on the $\Delta \mathrm{C}^{*}$ methodology (Gruber et al. 1996). There are important known biases in the $\Delta C^{*}$-derived $\mathrm{C}_{\text {ant }}$ estimates; they tend to be systematically too high in the upper ocean, too low in the deep ocean, and the global inventory is likely overestimated by about $7 \%$ (Matsumoto and Gruber 2005).

In addition to $\Delta p \mathrm{CO}_{2}$-derived flux estimates, we compare modeled annual-mean sea-air flux estimates to those derived from an ocean inversion employing GLODAP (Gruber et al. 2009). Inversion methods employ ocean general circulation models (OGCM) to solve for transport and mixing into the ocean interior: OGCMs are seeded with tracers at the ocean surface. Regional flux estimates are obtained by finding the linear combination of tracers from different regions that most closely match interior observations (Mikaloff Fletcher et al. 2006, 2007; Gruber et al. 2009). Ocean inversions have the distinct advantage of providing separate regionally resolved estimates for natural and anthropogenic flux components; however, since the ocean carbon data used to constrain the inversion require several years to collect, the flux estimates obtained are necessarily static in time and aliased by variability over the observational period. Furthermore, the inversion methodology is subject to errors in the databased estimates of $C_{a n t}$ and, as currently implemented, relies on time-invariant circulation fields from OGCMs with potential biases. The $\mathrm{C}_{\mathrm{ant}}$ flux estimates are not very sensitive to biases in the vertical distribution of $\Delta C^{*}$-derived $\mathrm{C}_{\mathrm{ant}}$; however, the globally integrated $\mathrm{C}_{\mathrm{ant}}$ fluxes scale in proportion to the $\mathrm{C}_{\mathrm{ant}}$ inventory bias (Mikaloff Fletcher et al. 2006) - thus we might expect these fluxes to be biased high by about $7 \%$ (cf. Matsumoto and Gruber 2005). We make use of the same regional definitions as Gruber et al. (2009), consolidating their original 30 regions into 12 aggregate regions.

\section{Results and discussion}

\section{a. Annual-mean surface properties}

The overall spatial pattern of modeled $\Delta p \mathrm{CO}_{2}$ $\left(\Delta p \mathrm{CO}_{2}=p \mathrm{CO}_{2}^{\mathrm{sw}}-p \mathrm{CO}_{2}^{\mathrm{atm}}\right)$ agrees reasonably well with observations (Table 2), with positive $\Delta p \mathrm{CO}_{2}$ values in the tropics and weakly negative values at midlatitudes. 
TABLE 2. Comparison of global annual-mean biogeochemical fields from CESM1 (mean over 1990-2000) and observational data. The Arctic is excluded from comparisons because of a paucity of observations. See Doney et al. (2009b) for a description of the metrics presented.

\begin{tabular}{|c|c|c|c|c|c|c|c|c|c|c|}
\hline \multirow[b]{2}{*}{ Variable } & \multirow[b]{2}{*}{ Units } & \multicolumn{3}{|c|}{ Mean } & \multicolumn{2}{|c|}{ Bias } & \multicolumn{2}{|c|}{ RMS error } & \multicolumn{2}{|c|}{ Correlation } \\
\hline & & Obs. & CORE & CPLD & CORE & CPLD & CORE & CPLD & CORE & CPLD \\
\hline $\mathrm{SST}^{\mathrm{a}}$ & ${ }^{\circ} \mathrm{C}$ & 19.12 & 19.15 & 19.49 & 0.0 & 0.4 & 0.5 & 1.1 & $>0.99$ & $>0.99$ \\
\hline $\mathrm{SSS}^{\mathrm{b}}$ & psu & 34.81 & 34.90 & 34.47 & 0.1 & -0.3 & 0.3 & 0.6 & 0.95 & 0.88 \\
\hline$p \mathrm{CO}_{2}^{\mathrm{c}}$ & ppmv & 358 & 367 & 367 & 8.6 & 8.7 & 17 & 19 & 0.80 & 0.77 \\
\hline$s \mathrm{DIC}^{\mathrm{d}}$ & $\mathrm{mmol} \mathrm{m}^{-3}$ & 2082 & 2068 & 2070 & -14 & -13 & 29 & 28 & 0.97 & 0.96 \\
\hline$s \mathrm{Alk}^{\mathrm{e}}$ & $\mathrm{mmol} \mathrm{m}^{-3}$ & 2377 & 2353 & 2352 & -25 & -25 & 33 & 35 & 0.73 & 0.70 \\
\hline $\mathrm{RF}^{\mathrm{f}}$ & & 10 & 10 & 11 & 0.2 & 0.5 & 0.6 & 0.8 & 0.97 & 0.97 \\
\hline $\mathrm{C}_{\mathrm{ant}}^{\mathrm{g}}$ & $\mathrm{mol} \mathrm{m}^{-2}$ & $\begin{array}{c}27 \\
(101)\end{array}$ & $\begin{array}{l}21 \\
(85)\end{array}$ & $\begin{array}{l}22 \\
(89)\end{array}$ & -5.4 & -4.5 & 9.3 & 8.9 & 0.86 & 0.87 \\
\hline CFC- $11^{\mathrm{h}}$ & $\mu \mathrm{mol} \mathrm{m}^{-2}$ & $\begin{array}{c}1.6 \\
\left(5.15 \times 10^{8}\right)\end{array}$ & $\begin{array}{c}1.4 \\
\left(4.73 \times 10^{8}\right)\end{array}$ & $\begin{array}{c}1.5 \\
\left(4.97 \times 10^{8}\right)\end{array}$ & -0.2 & -0.1 & 0.8 & 0.7 & 0.86 & 0.89 \\
\hline
\end{tabular}

\footnotetext{
${ }^{\text {a }}$ Sea surface temperature observations from Hurrell et al. (2008).

${ }^{\mathrm{b}}$ Sea surface salinity observations from $W O A$.

${ }^{\mathrm{c}}$ Sea surface $p \mathrm{CO}_{2}$ observations from Takahashi et al. (2009).

${ }^{\mathrm{d}}$ Sea surface dissolved inorganic carbon (salinity normalized) observations from GLODAP.

${ }^{\text {e }}$ Sea surface salinity-normalized alkalinity observations from GLODAP.

${ }^{\mathrm{f}}$ Sea surface Revelle factor computed from GLODAP and WOA data.

${ }^{g}$ Column inventory of anthropogenic $\mathrm{CO}_{2}$ observations from GLODAP, excluding marginal seas and Arctic Ocean. Numbers in parentheses below means are the respective global inventories $(\mathrm{PgC})$ computed on the model grid.

${ }^{\mathrm{h}}$ Column inventory of CFC-11 observations from GLODAP, excluding marginal seas and Arctic Ocean. Numbers in parentheses below means are the respective global inventories (mol) computed on the model grid.
}

Modeled $\Delta p \mathrm{CO}_{2}$ is larger than observed in the eastern equatorial Pacific and over much of the Southern Ocean north of about $60^{\circ} \mathrm{S}$, especially in the Indian Ocean sector (Figs. 1b,c). The term $\Delta p \mathrm{CO}_{2}$ is underestimated, by contrast, in the polar Southern Ocean, particularly in the coupled model (Figs. 1b,c); in this region, the model predicts $\Delta p \mathrm{CO}_{2}$ values of the opposite sign to those of Takahashi et al. (2009).

Both model configurations capture the overall spatial structure in annual-mean salinity-normalized surface DIC and alkalinity, evident in high-correlation coefficients relative to GLODAP (Table 2). However, modeled salinity-normalized surface DIC and alkalinity concentrations tend to be too low over much of the ocean, with global-mean biases of about -13 and $-25 \mathrm{mmol} \mathrm{m}^{-3}$, respectively (Table 2). Qualitatively, there is some similarity between the spatial distribution of positive biases in $\Delta p \mathrm{CO}_{2}$ and positive biases in $s \mathrm{DIC}$ (Fig. 1), with patches of elevated $s$ DIC in the equatorial Pacific and Southern Ocean. The correlation between these bias fields is not significant at the $95 \%$ level, however, and other factors, such as alkalinity, contribute to variations in the $s \mathrm{DIC}-p \mathrm{CO}_{2}^{\mathrm{sw}}$ relationship. It is also important to note that $p \mathrm{CO}_{2}^{\text {sw }}$ computed from GLODAP surface fields is not strictly consistent with Takahashi et al. (2009) since $p \mathrm{CO}_{2}$ is a nonlinear function of the gridded fields. Salinity-normalized surface alkalinity is underestimated virtually everywhere in both model configurations, especially in the North Pacific (Table 2), with the exception of equatorial regions in the Pacific and Indian Oceans and in the Weddell Sea (Figs. 1h,i). Alkalinity is, in fact, biased low throughout the upper water column in both models but over estimated at depth (Moore et al. 2013). Deficiencies in the prescribed dissolution curve for sinking $\mathrm{CaCO}_{3}$ may contribute to these biases, as the near-surface rain ratio and export magnitudes are reasonable (Moore et al. 2013).

In a closed system, DIC and alkalinity induce effects of opposing tendency (but unequal magnitude) on $p \mathrm{CO}_{2}^{\mathrm{sw}}$ : low biases in DIC depress $p \mathrm{CO}_{2}^{\mathrm{sw}}$ values, while low alkalinity pushes $p \mathrm{CO}_{2}^{\mathrm{sw}}$ higher. Thus, in regions where DIC is low, the effect of low alkalinity may result in elevated $p \mathrm{CO}_{2}^{\mathrm{sw}}$. The northeastern Pacific, for instance, has both negative DIC and alkalinity biases but positive $\Delta p \mathrm{CO}_{2}$ bias (Fig. 1). The negative bias in surface alkalinity would result in a negative bias in $\mathrm{DIC}_{\mathrm{eq}}$ of about $50-60 \mathrm{mmol} \mathrm{m}^{-3}$ over much of the ocean in the coupled model (see supplementary materials, Fig. S1).

Much of the surface ocean is not at equilibrium with respect to atmospheric $\mathrm{CO}_{2}$, and biases in $\mathrm{DIC}_{\text {eq }}$ provide only a qualitative sense of surface chemistry impacts on $\mathrm{CO}_{2}$ uptake. Low alkalinity causes the surface ocean to more quickly saturate with respect to a perturbation in atmospheric $\mathrm{CO}_{2}$, thereby contributing to diminished $\mathrm{CO}_{2}$ uptake in transient simulations. The Revelle factor $\left[\mathrm{RF}=\mathrm{DIC} / p \mathrm{CO}_{2}\left(\partial p \mathrm{CO}_{2} / \partial \mathrm{DIC}\right)\right]$ quantifies this effect: 


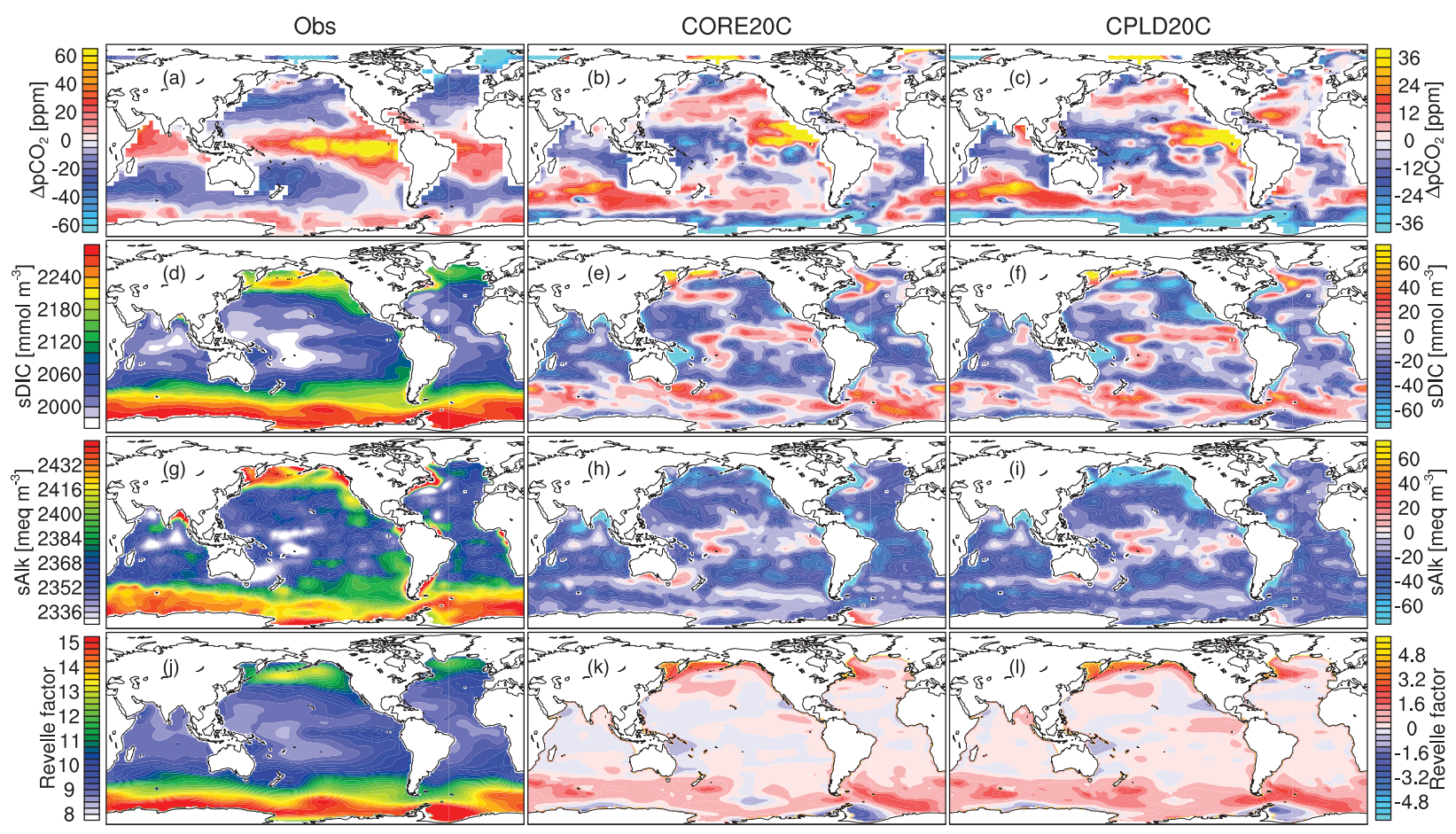

FIG. 1. (left) Observationally based climatologies of surface fields. Biases relative to observations in (center) CORE20C, and (right) CPLD20C. (a)-(c) Annual-mean sea-air $p \mathrm{CO}_{2}$ difference ( $\Delta p \mathrm{CO}_{2}$; Takahashi et al. 2009). (d)-(f) Salinity-normalized dissolved inorganic carbon, (g)-(i) salinity-normalized alkalinity, and (j)-(1) Revelle factor (Key et al. 2004). The Revelle factor was computed analytically from the thermodynamic equations.

a high RF indicates a smaller change in DIC per unit change in $p \mathrm{CO}_{2}$; therefore, a high $\mathrm{RF}$ results in reduced $\mathrm{CO}_{2}$ uptake from the anthropogenic transient. Negative biases in alkalinity contribute to a net positive bias in the model's global-mean RF (Table 2; Fig. 1). The RF is sensitive to the DIC:alkalinity ratio; thus, there is some spatial correspondence between positive biases in DIC and the RF (Fig. 1).

Temperature and salinity also affect carbonate equilibrium chemistry. Weak salinity restoring in the CORE-forced runs and the use of observationally based forcing data lead to smaller biases in sea surface temperature and salinity in this integration relative to the coupled model (Table 2). Since $\mathrm{CO}_{2}$ solubility increases with decreasing temperature, biases in $\mathrm{DIC}_{\text {eq }}$ are negatively correlated with biases in SST (Fig. S1). For instance, the coupled model SST tends to be too warm in subtropical eastern boundary currents and too cold at high latitudes and in the Gulf Stream and Kuroshio regions (Danabasoglu et al. 2012). The most pronounced positive effects of SST on $\mathrm{DIC}_{\mathrm{eq}}$ in the coupled model are evident in the Southern Ocean and south of Greenland, where SST are too cold (Fig. S1). These effects offset the negative influence of low alkalinity somewhat but overall the total $\mathrm{DIC}_{\mathrm{eq}}$ bias is quite similar to the alkalinity effect
(Fig. S1), demonstrating that alkalinity biases dominate over those in SST.

Examination of the surface DIC and alkalinity fields requires some care since the observations reflect processes not in the models. For instance, large but localized negative biases in salinity-normalized DIC and alkalinity in the Atlantic and Indian Ocean basins reflect terrestrial carbon and weathering inputs from the Congo, Amazon, and Ganges/Brahmaputra Rivers that are not included in the model (Fig. 1).

\section{b. Seasonality}

In the stratified subtropical ocean, seasonal variability in $p \mathrm{CO}_{2}^{\mathrm{sw}}$ is predominantly related to changes in SST: summer warming increases $p \mathrm{CO}_{2}^{\mathrm{sw}}$, whereas winter cooling drives decreases it (Takahashi et al. 2002). In contrast, in the subpolar ocean, winter is characterized by opposing effects of cold SSTs and entrainment of $\mathrm{CO}_{2}$-rich deep water by vertical mixing-in summer, warming drives $p \mathrm{CO}_{2}^{\mathrm{sw}}$ up, while biological $\mathrm{CO}_{2}$ drawdown by phytoplankton drives it down. CESM1 captures the resulting seasonality in $p \mathrm{CO}_{2}^{\mathrm{sw}}$ quite well over most oceanic regions (Fig. 2). Two notable exceptions are the polar Southern Ocean and the high-latitude North Atlantic $\left(49^{\circ}-80^{\circ} \mathrm{N}\right)$. 

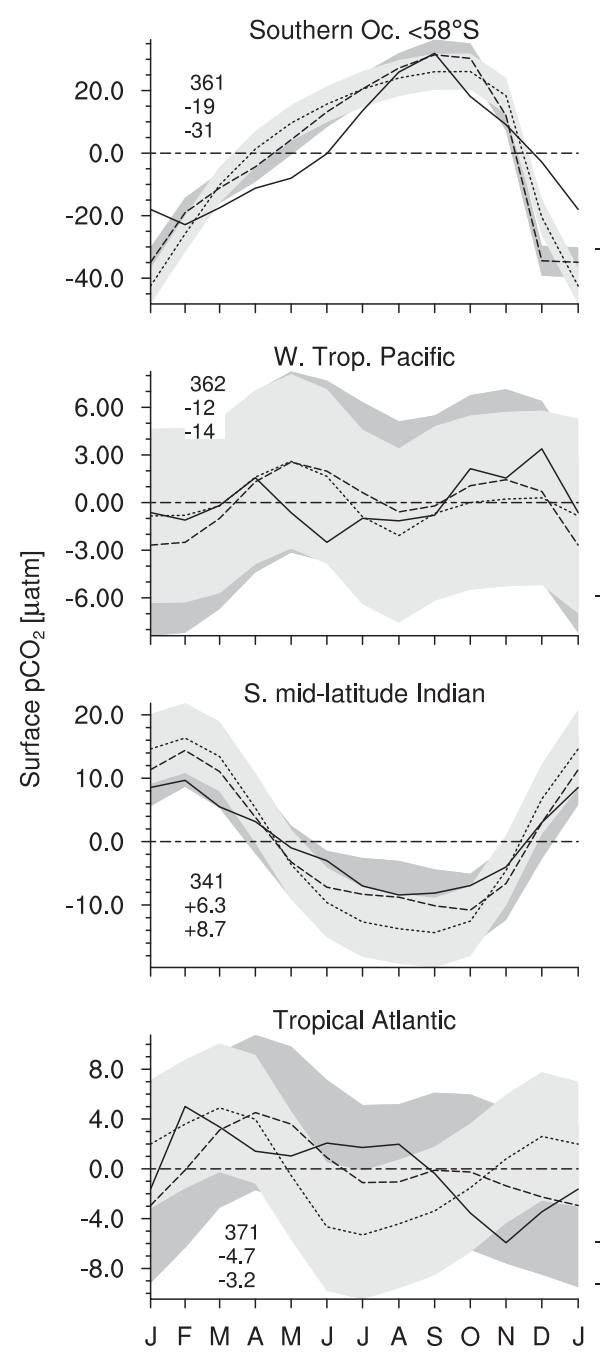
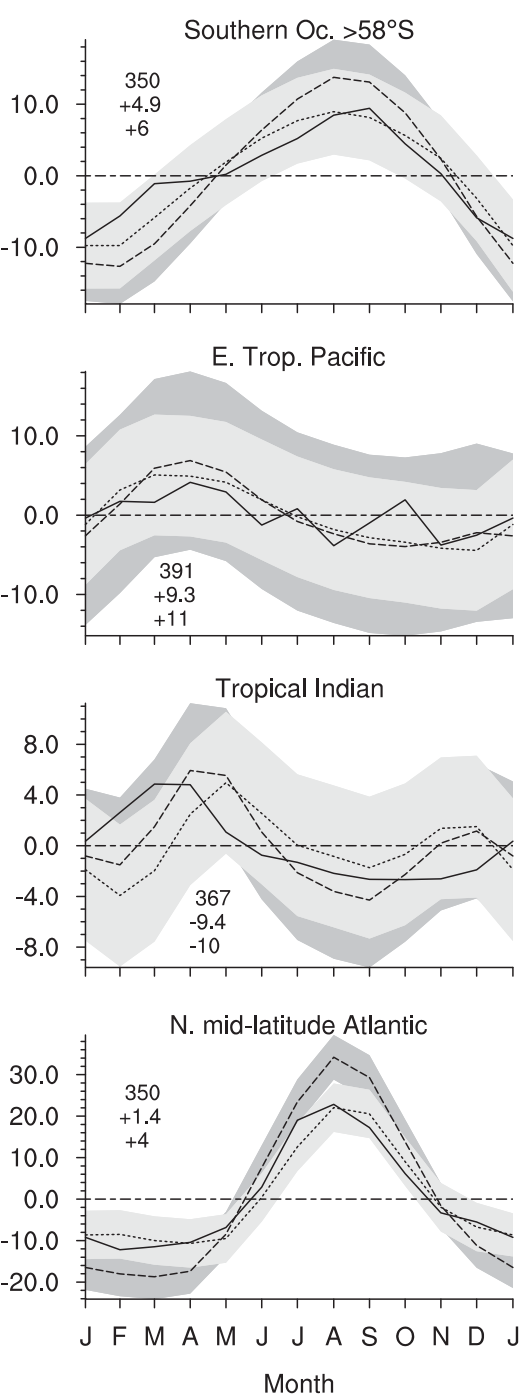
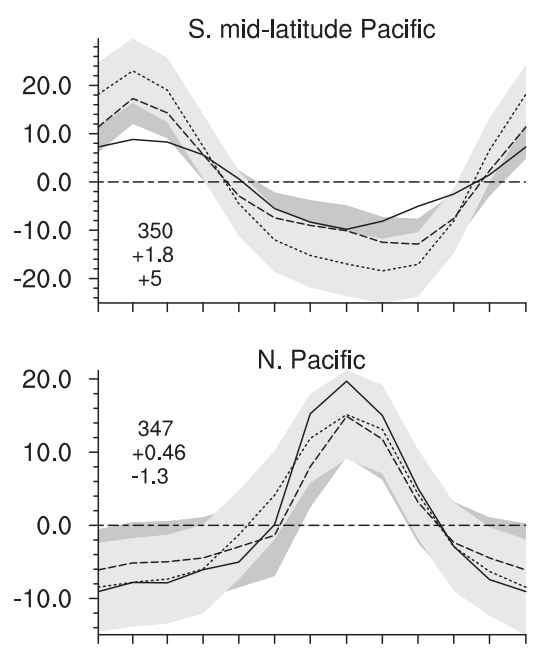

S. mid-latitude Atlantic

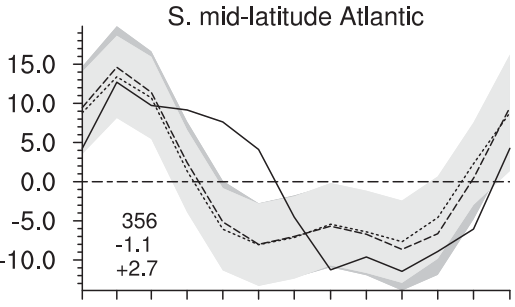

N. high-latitude Atlantic $<80^{\circ} \mathrm{N}$

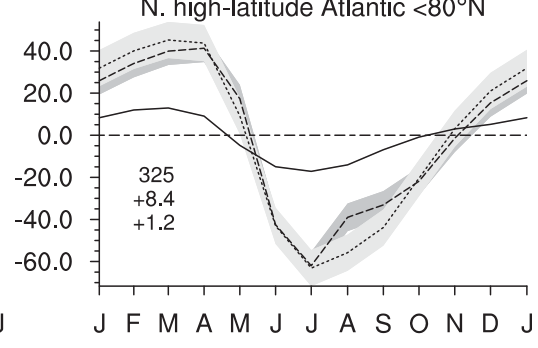

FIG. 2. Seasonal cycle of $p \mathrm{CO}_{2}$ by region from the monthly climatology of Takahashi et al. (2009; solid), CORE20C (dashed), and CPLD20C (dotted). Model data are from years 1995-2005, bracketing reference year 2000 used in the observations. The annual mean has been subtracted from each series; in each plot, the column of numbers shows, in order from top to bottom, the annual mean (ppm) of the observations then the CORE20C and CPLD20C annual-mean biases. Shaded regions show the range of interannual variability $( \pm 1 \sigma)$ in CORE20C (dark gray), and CPLD20C (light gray) for the same 10-yr period. Regional definitions are the same as those in Gruber et al. (2009).

In the polar Southern Ocean, annual-mean $p \mathrm{CO}_{2}^{\mathrm{sw}}$ is substantially lower in the model than in observations (Figs. 1,2) and the model predicts stronger seasonality, with much lower austral summer December-February (DJF) $p \mathrm{CO}_{2}^{\mathrm{sw}}$ values than in the Takahashi et al. (2009) climatology (Fig. 2). The cause of these biases may involve overestimation of summertime net primary productivity. Summertime mixed layer depths along the Antarctic Circumpolar Current (ACC) are too shallow in the model by 20-50 m (Danabasoglu et al. 2012; Moore et al. 2013). Thus, the seasonal drawdown of DIC occurs in a mixed layer that is much shallower than observed; light limitation of phytoplankton growth rates is therefore underestimated, leading to reduced $p \mathrm{CO}_{2}$ in the austral summer and a depressed annual mean. The sparsity of observations in the Southern Ocean, particularly during winter months, may also contribute. To compensate for winter data gaps, Takahashi et al. (2009) assume that $p \mathrm{CO}_{2}$ increases linearly with time in ice-covered waters. This assumption may unrealistically inflate the annual-mean $p \mathrm{CO}_{2}^{\mathrm{sw}}$. Furthermore, the coarse resolution $\left(4^{\circ} \times 5^{\circ}\right)$ of the Takahashi et al. (2009) climatology may contribute to the discrepancy, particularly given the heterogeneous nature of polar Southern Ocean phytoplankton blooms and other processes controlling $p \mathrm{CO}_{2}^{\mathrm{sw}}$ (Moore and $\mathrm{Ab}$ bott 2000; Doney et al. 2003; Arrigo et al. 2008a,b).

In the North Atlantic $\left(49^{\circ}-80^{\circ} \mathrm{N}\right), \mathrm{CESM} 1$ predicts an annual-mean $p \mathrm{CO}_{2}^{\mathrm{sw}}$ that is comparable to the observations, 


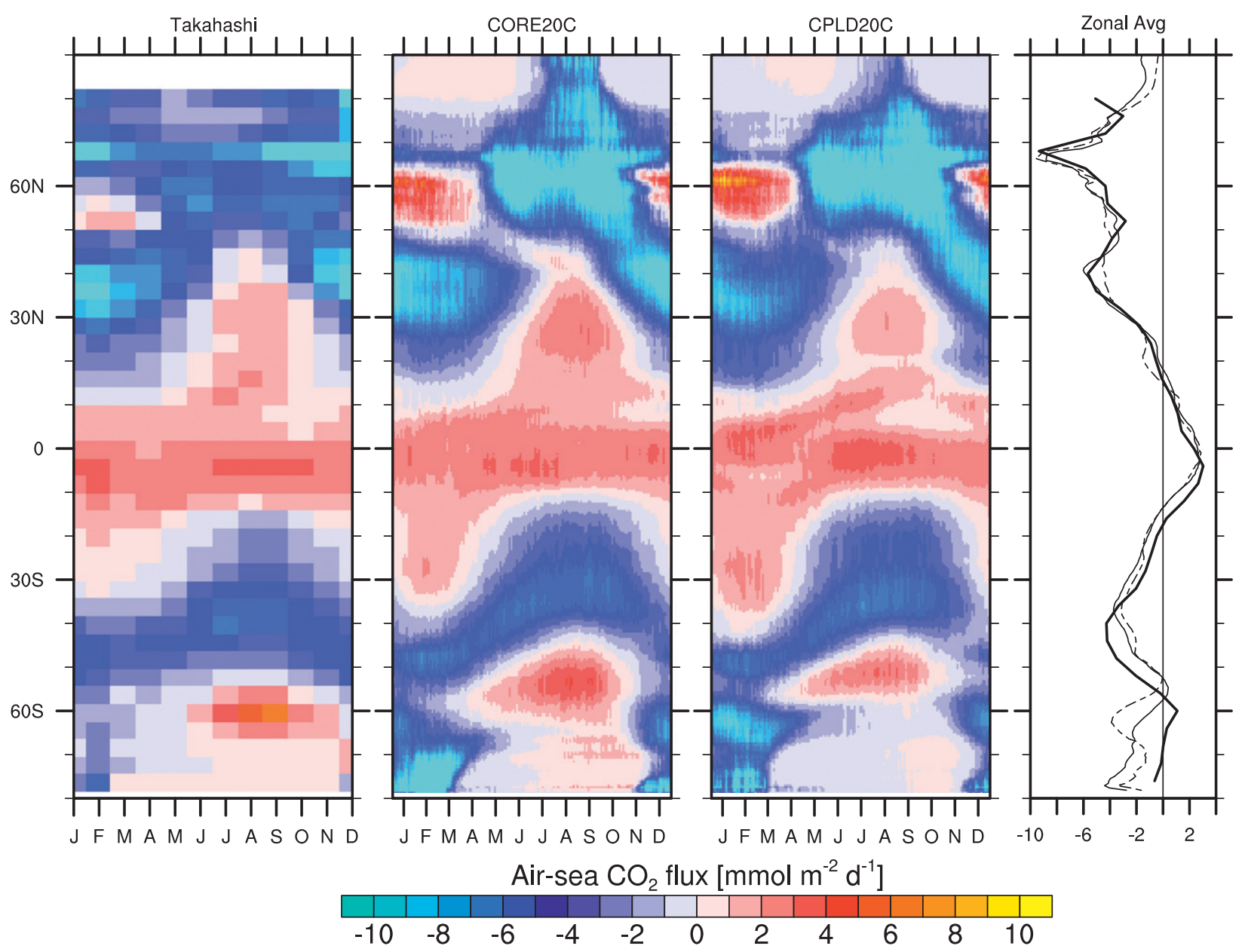

FIG. 3. Sea-air $\mathrm{CO}_{2}$ flux from the monthly climatology of Takahashi et al. (2009), CORE20C, and CPLD20C (negative = ocean uptake). (right) The annual zonal-mean flux from observations (thick solid), CORE20C (thin solid), and CPLD20C (dashed).

but the amplitude of the seasonal cycle in the model is $\sim 5$-fold larger. Summer $\mathrm{CO}_{2}$ drawdown may be overestimated by the model; high-chlorophyll biases in this region indicate that the magnitude of the simulated Arctic phytoplankton bloom is too strong (Moore et al. 2013). Winter maximum mixed layer depths are too deep in this region (Danabasoglu et al. 2012; Moore et al. 2013), likely leading to excessive DIC entrainment into surface waters. Data sparsity may also contribute to this discrepancy, resulting in an aliased seasonal cycle in the observations.

While the amplitude of the high-latitude seasonal cycle in $p \mathrm{CO}_{2}^{\mathrm{sw}}$ is generally much larger than interannual variability (at the large scales reflected by regional means), the opposite is true in the tropics (Fig. 2). Much of the interannual variability in carbon cycling in this region is related to ENSO, discussed in detail below.

\section{c. Air-sea fluxes}

Figure 3 shows the seasonal cycle in zonally averaged sea-air flux from the Takahashi et al. (2009) monthly climatology, CORE20C, and CPLD20C. Overall, there is good agreement between the model and the observations: outgassing in the tropics throughout the year and a strong seasonal cycle in sea-air flux at high latitudes. In terms of the annual-mean flux (Fig. 3, far right), CESM closely matches the $\Delta p \mathrm{CO}_{2}$-based climatology, except in the Southern Ocean.

In both model configurations, contemporary $\mathrm{CO}_{2}$ uptake is weaker than $\Delta p \mathrm{CO}_{2}$-based flux estimates between about $40^{\circ}$ and $55^{\circ} \mathrm{S}$; whereas south of $60^{\circ} \mathrm{S}$ the models show stronger uptake (Fig. 3, far right) — consistent with the biases in $\Delta p \mathrm{CO}_{2}$ (Fig. 1). In the CORE-forced integration, this results in compensating biases, yielding close correspondence with observationally based zonally integrated flux estimates south of $44^{\circ} \mathrm{S}$ (Fig. 4); however, coupled model $\mathrm{CO}_{2}$ uptake in this region is about $0.15 \mathrm{PgC} \mathrm{yr}^{-1}$ greater than in CORE20C. Much of this discrepancy results from anomalous $\mathrm{CO}_{2}$ uptake in CPLD20C around $60^{\circ} \mathrm{S}$. Southern Hemisphere sea ice coverage is far too extensive in CPLD20C; the total sea 


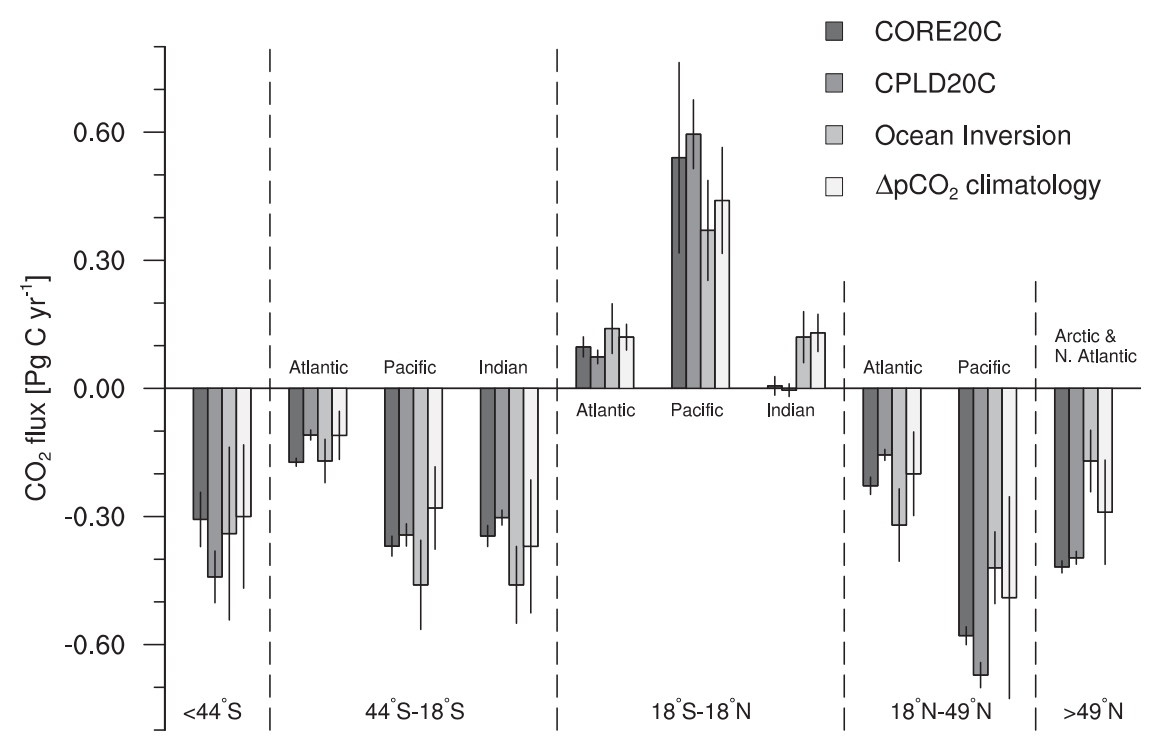

FIG. 4. Zonally integrated contemporary sea-air $\mathrm{CO}_{2}$ fluxes by ocean basin (negative $=$ ocean uptake). Data from CORE20C and CPLD20C are the mean fluxes over the period 19902000. Also shown are the ocean inversion estimates from Gruber et al. (2009) and $\Delta p \mathrm{CO}_{2}$-based estimates from Takahashi et al. [2009; regional averaging and error computation done by Gruber et al. (2009)]. For the observationally based estimates, error bars are taken from Gruber et al. (2009); the model error bars show $\pm 1 \sigma$ for the 11 -yr period.

ice area is consistently about $62 \%\left(\sim 4.0 \times 10^{6} \mathrm{~km}^{2}\right)$ greater than satellite observations over the seasonal cycle (Landrum et al. 2012). This is likely due to westerly winds in the coupled model that are stronger than observed (Danabasoglu et al. 2012); sea ice coverage in CORE20C, by contrast, is reasonable. As a result of extensive sea ice in CPLD20C, austral summer $\mathrm{CO}_{2}$ uptake south of $60^{\circ} \mathrm{S}$ is weakened and shifted northward relative to that in CORE20C (Fig. 3). However, in spite of stronger Southern Ocean winds in the coupled model, extensive ice cover dampens austral winter outgassing (Fig. 3); thus, on an annual time scale, CPLD20C yields a greater Southern Ocean sink for contemporary $\mathrm{CO}_{2}$ than CORE20C or the $\Delta p \mathrm{CO}_{2}$-based flux estimates (Fig. 4).

In the tropics, there is close correspondence between modeled and observed zonal-mean fluxes at the global scale (Fig. 3). An examination of zonally integrated fluxes within each basin indicates some regional disparities leading to compensating biases (Fig. 4). The equatorial Pacific in both model configurations has outgassing rates higher than in either observational dataset, while the model outgassing rates are slightly low (but perhaps not significantly) relative to observations in the equatorial Atlantic. The tropical Indian Ocean has sea-air $\mathrm{CO}_{2}$ flux rates near zero in the model, whereas the observations indicate a source of about 0.1

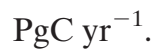

Contemporary $\mathrm{CO}_{2}$ fluxes can be partitioned into preindustrial (natural) and anthropogenic components
$\left(\mathrm{C}_{\mathrm{ant}}\right)$. The Southern Ocean has the greatest zonally integrated uptake of $\mathrm{C}_{\text {ant }}$ (Fig. 5). The two model configurations return very similar estimates of Southern Ocean $\mathrm{C}_{\text {ant }}$ uptake, about $0.2 \mathrm{PgC} \mathrm{yr}^{-1}$ less than the ocean inversion estimates (Fig. 5; Gruber et al. 2009). However, while the estimates of Southern Ocean $\mathrm{C}_{\mathrm{ant}}$ uptake are similar between the two models, the Southern Ocean in the CORE-forced integration has stronger outgassing of natural $\mathrm{CO}_{2}$. Southern Ocean uptake of $\mathrm{C}_{\mathrm{ant}}$ is comparable between the two model configurations; thus, weaker contemporary $\mathrm{CO}_{2}$ uptake in the CORE-forced integration is a result of stronger preindustrial outgassing (Fig. 4). However, despite being stronger than in the coupled integration, preindustrial outgassing in CORE1850 is still about $0.2 \mathrm{PgCyr}^{-1}$ lower than ocean inversion estimates (Fig. 5). This is consistent with generally weak ventilation and vertical exchange in the CESM models, something seen previously in CCSM3 (Thornton et al. 2009; Wang et al. 2012).

\section{d. Multidecadal $\mathrm{pCO}$ sw trends}

As the ocean absorbs carbon from the atmospheric $\mathrm{CO}_{2}$ perturbation surface ocean DIC increases, which drives increases in $p \mathrm{CO}_{2}^{\mathrm{sw}}$ at a rate that slightly lags $p \mathrm{CO}_{2}^{\text {atm }}$, reflecting vertical mixing and sea-air exchange time scales (Le Quéré et al. 2010). If $p \mathrm{CO}_{2}^{\text {sw }}$ increases at the same rate as $p \mathrm{CO}_{2}^{\mathrm{atm}}$, there should be no change in $\Delta p \mathrm{CO}_{2}$. Indeed, global-mean trends in $\Delta p \mathrm{CO}_{2}$ indicate that ocean $p \mathrm{CO}_{2}$ approximately tracked $p \mathrm{CO}_{2}^{\text {atm }}$ in both 


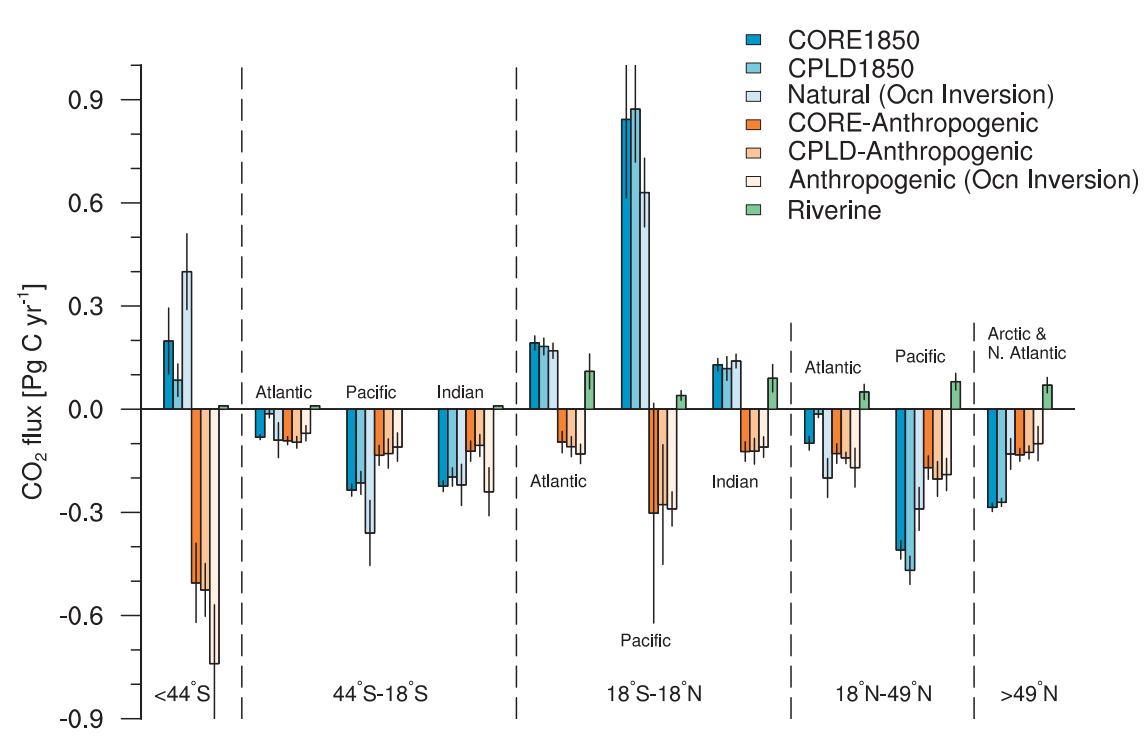

FIG. 5. Zonally integrated sea-air $\mathrm{CO}_{2}$ flux components by ocean basin (negative $=$ ocean uptake). Bars plotted in blue shades show preindustrial (natural) fluxes, whereas red shades show anthropogenic fluxes. Data from CORE20C and CPLD20C are the mean fluxes over the period 1990-2000. Also shown are the ocean inversion estimates from Gruber et al. (2009). For the observationally based estimates, error bars are taken from Gruber et al. (2009); the model error bars show $\pm 1 \sigma$ for the 11 -yr period. See Gruber et al. (2009) for further details on the riverine flux contributions.

CORE20C and CPLD20C, yielding weak trend in $\Delta p \mathrm{CO}_{2}$. Over the period 1981-2005 $p \mathrm{CO}_{2}^{\mathrm{atm}}$ increased at about $1.59 \mathrm{ppm} \mathrm{yr}^{-1}$; meanwhile, the global-mean $\Delta p \mathrm{CO}_{2}$

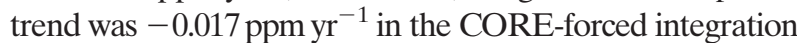
and $-0.05 \mathrm{ppm} \mathrm{yr}^{-1}$ in the coupled model. Increasingly negative $\Delta p \mathrm{CO}_{2}$ values drive increasing ocean uptake of $\mathrm{CO}_{2}$.

In spite of weakly negative global-mean trends, regional variability in $\Delta p \mathrm{CO}_{2}$ trends is evident in both model configurations (Figs. 6a,b). The term $p \mathrm{CO}_{2}^{\mathrm{sw}}$ increased faster than $p \mathrm{CO}_{2}^{\text {atm }}$ in the subtropical Pacific and the Arctic Ocean in CORE20C and CPLD20C. Positive $\Delta p \mathrm{CO}_{2}$ trends are also evident in the subantarctic in CORE20C. Conversely, the North Atlantic and polar Southern Ocean exhibit negative trends in $\Delta p \mathrm{CO}_{2}$ in both model configurations, indicative of surface ocean $p \mathrm{CO}_{2}$ falling behind that of the atmosphere.

Comparison of modeled trends with observationally based trend estimates shows regions of both agreement and disagreement. For instance, Le Quéré et al. (2010) found that $p \mathrm{CO}_{2}^{\mathrm{sw}}$ was increasing faster than $p \mathrm{CO}_{2}^{\mathrm{atm}}$ in the western tropical Pacific and the subantarctic region of the Southern Ocean; $p \mathrm{CO}_{2}^{\mathrm{sw}}$ increased more slowly than $p \mathrm{CO}_{2}^{\mathrm{atm}}$ in the North and South Pacific. There is some consistency between these results and trend in CORE20C, although considerable spatial heterogeneity complicates comparisons (Fig. 6). Le Quéré et al. (2010) found that $p \mathrm{CO}_{2}^{\mathrm{sw}}$ was increasing faster than $p \mathrm{CO}_{2}^{\mathrm{atm}}$ in the North Atlantic, which is not consistent with the model results. However, McKinley et al. (2011), who examined North Atlantic $p \mathrm{CO}_{2}^{\mathrm{sw}}$ trends in observations, found that between 1981 and 2009 North Atlantic $p \mathrm{CO}_{2}^{\mathrm{sw}}$ increased uniformly over the region at a rate just below that of $p \mathrm{CO}_{2}^{\text {atm }}$. These authors demonstrate that climate variability can cause $p \mathrm{CO}_{2}^{\mathrm{sw}}$ trends to deviate from $p \mathrm{CO}_{2}^{\text {atm }}$ trends on decadal time scales (see also Thomas et al. 2008), but over the long term $(+25 \mathrm{yr})$, $p \mathrm{CO}_{2}^{\mathrm{sw}}$ in the North Atlantic basically tracks $p \mathrm{CO}_{2}^{\mathrm{atm}}$.

Metzl (2009) analyzed observations in the Indian Ocean sector of the Southern Ocean (south of $20^{\circ} \mathrm{S}$ ), finding a rate of increase in surface ocean $p \mathrm{CO}_{2}^{\mathrm{sw}}$ equivalent to $2.11 \pm 0.07 \mu \mathrm{atm} \mathrm{yr}^{-1}(1 \mathrm{~atm} \equiv 1013.25$ $\mathrm{hPa}$ ) between 1991 and 2007 (i.e., faster than the respective rise in $p \mathrm{CO}_{2}^{\mathrm{atm}}$ of $1.72 \mu \mathrm{atm} \mathrm{yr}^{-1}$ ) leading to a positive trend in $\Delta p \mathrm{CO}_{2}$ and weakened uptake. Results from CORE20C show comparable significant increases in $p \mathrm{CO}_{2}^{\mathrm{sw}}$ in a similar region; in fact, the Indian Ocean sector of the Southern Ocean appears to have the greatest rate of $p \mathrm{CO}_{2}^{\mathrm{sw}}$ increase in the subantarctic.

While $p \mathrm{CO}_{2}^{\mathrm{sw}}$ is affected by temperature, which impacts $\mathrm{CO}_{2}$ solubility, nonthermal (i.e., DIC and alkalinity concentrations) factors dominate $p \mathrm{CO}_{2}^{\mathrm{sw}}$ variability. Figures 6e, f shows the trend in $p \mathrm{CO}_{2}^{\mathrm{sw}}$ between 1980 and 2005 that is attributable to trends in SST; subtracting temperatureinduced changes in $p \mathrm{CO}_{2}$ from the total change provides a measure of the nonthermally induced $p \mathrm{CO}_{2}^{\mathrm{sw}}$ change (Figs. 6g,h). In both model configurations, the thermally 


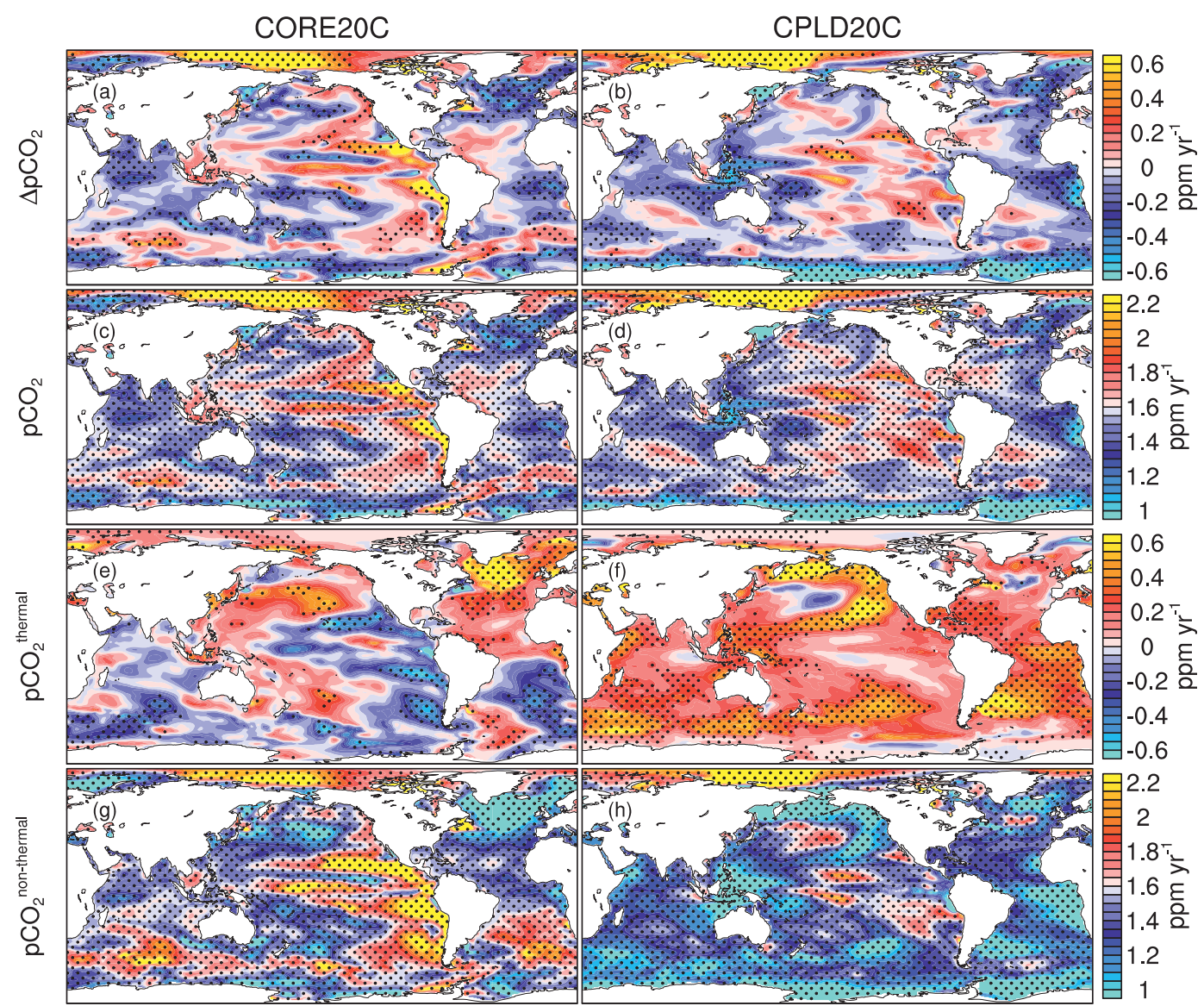

FIG. 6. (a),(b) Trends in $\Delta p \mathrm{CO}_{2}\left(\Delta p \mathrm{CO}_{2}=p \mathrm{CO}_{2}^{\mathrm{sw}}-p \mathrm{CO}_{2}^{\mathrm{atm}}\right)$ between 1981 and 2005. (c),(d) Trends in $p \mathrm{CO}_{2}^{\mathrm{sw}}$. (e),(f) Trends in $p \mathrm{CO}_{2}^{\mathrm{sw}}$ driven by changes in sea surface temperature over the same period (Takahashi et al. 2002). (g),(h) Trends in $p \mathrm{CO}_{2}^{\mathrm{sw}}$ not driven by temperature (over most of the globe this component is mostly driven by changes in dissolved inorganic carbon and secondarily affected by changes in alkalinity, salinity, and freshwater; these latter effects can be locally important). (left) Results from CORE20C and (right) CPLD20C. Note the differing color bars: for the first and third rows, the color bar is centered on zero; in the second and bottom row, it is centered on $1.6 \mathrm{ppm} \mathrm{yr}^{-1}$, which is the rate at which $p \mathrm{CO}_{2}^{\text {atm }}$ increased over the period shown. Stippling denotes significance at the $95 \%$ confidence level.

induced portion of the $p \mathrm{CO}_{2}^{\mathrm{sw}}$ trend is the smaller component, which is consistent with observations over the same period (e.g., McKinley et al. 2011). Notably, however, the thermal component in the coupled model is stronger and more uniformly positive than in the CORE-forced integrations (Figs. 6c,d). This is due to greater trends in SST in the coupled model, in which twentieth-century warming is about $0.4^{\circ} \mathrm{C}$ in excess of that observed (Gent et al. 2011). The spatial patterns of warming-induced $p \mathrm{CO}_{2}^{\mathrm{sw}}$ trends in CORE20C and CPLD20C are not similar. The North Atlantic stands out as a large coherent region of significant warmingrelated trends in CORE20C, a feature absent from CPLD20C (Figs. 6e,f). The coupled model exhibits significant warming-induced trends in the subtropical gyres and subantarctic (Fig. 6f).

\section{e. Multidecadal $\mathrm{CO}_{2}$ flux trends}

Sea-air flux in the steady-state preindustrial ocean is thought to have been about $+0.5 \mathrm{PgC} \mathrm{yr}^{-1}$ because of the outgassing of carbon inputs from rivers (Fig. 5; Gruber et al. 2009). Since CESM1(BGC) does not currently represent riverine carbon contributions, the longterm mean of global-scale natural $\mathrm{CO}_{2}$ fluxes is near zero in both model configurations (Figs. 7a,b). The experimental design of the CORE-forced integrations precludes substantive inferences about trends prior to 1948; however, we note that the long-term trends in seaair fluxes in CORE1850 are near zero (Table 3).

There is a moderate positive (outgassing) trend in natural $\mathrm{CO}_{2}$ flux over 1970-2005 in the CORE-forced integration (Fig. 7a; Table 3). Since this trend is greater 



FIG. 7. Sea-air $\mathrm{CO}_{2}$ fluxes (negative $=$ ocean uptake) in the (left) CORE-forced and (right) coupled integrations. (a),(b) Globally integrated fluxes, (c),(d) Southern Ocean (south of $\left.44^{\circ} \mathrm{S}\right)$, and (e),(f) North Atlantic $\left(36^{\circ}-76^{\circ} \mathrm{N}\right)$. In each panel, the solid black line shows the 1850 control (preindustrial fluxes), the dashed line shows the twentiethcentury transient (contemporary), and the gray line shows the difference (after removal of interannual variability in preindustrial fluxes): anthropogenic $\mathrm{CO}_{2}$. The CORE forcing applies to the period 1948-2007, but was recycled (see methods) to span the period 1850-2007. Vertical lines in panels (a),(c), and (e) show the beginning of each 60-yr forcing cycle; climate-driven variability and trends prior to 1948 are not real, thus this period is grayed out.

in the CORE-forced integration than in the coupled model, the trajectories of globally integrated contemporary and $\mathrm{C}_{\mathrm{ant}}$ fluxes are more similar in the coupled model (Fig. 7b; Table 3).

The Southern Ocean and North Atlantic are two key regions for oceanic carbon uptake. These regions had the greatest trends in contemporary, and hence $\mathrm{C}_{\mathrm{ant}}$, uptake over the globe (Table 3). The trends in North Atlantic sea-air $\mathrm{CO}_{2}$ flux components are similar between the models (Table 3; Figs. 7e,f) and, consistent with the flux trend, $\Delta p \mathrm{CO}_{2}$ is decreasing (becoming more negative; Figs. 6a,b).

The behavior of the models in the Southern Ocean is markedly different. In particular, there are strong trends toward outgassing of natural $\mathrm{CO}_{2}$ evident in the COREforced integration over the forcing period (1948-2005); the coupled model has only very weak trends (Figs. 7c,d; Table 3). The trends in the CORE-forced integration are clearly a manifestation of the forcing, not model drift: the last three 60 -yr natural $\mathrm{CO}_{2}$ flux time series corresponding to the successive forcing cycles (i.e., model years $61-120,121-180$, and 181-240) are nearly identical.

Southern Ocean $\mathrm{CO}_{2}$ flux trends in the CORE-forced integrations are attributable to intensification of the westerly winds. Stronger westerlies accelerate the Antarctic Circumpolar Current, driving enhanced upwelling of DIC at the Antarctic divergence in the model (e.g., 
TABLE 3. Linear temporal trends in sea-air flux of natural anthropogenic (Anthr.) and contemporary (Contemp.) $\mathrm{CO}_{2}$. In each column, the values for 1) CORE-forced and 2) coupled integrations are separated by a comma. Trends over the period 1850-2005 from the COREforced integrations should be interpreted as model drift. Units are mmol m${ }^{-2} \mathrm{yr}^{-2}$. "Ns" denotes trends not significant at the $95 \%$ confidence level.

\begin{tabular}{lcccc}
\hline \multicolumn{1}{c}{ Region } & $1850-2005$ natural & $1970-2005$ natural & Anthr. & Contemp. \\
\hline Global & $\mathrm{ns}, 0.06$ & $2.78, \mathrm{~ns}$ & $-4.47,-5.76$ & $-7.25,-6.24$ \\
Southern Ocean $<58^{\circ} \mathrm{S}$ & $\mathrm{ns},-0.09$ & $9.38, \mathrm{~ns}$ & $-7.12,-13.50$ & $-16.50,-13.98$ \\
Southern Ocean $>58^{\circ} \mathrm{S}$ & $\mathrm{ns}, 0.40$ & $\mathrm{~ns}, 2.45$ & $\mathrm{~ns},-8.48$ & $-11.83,-10.93$ \\
South midlatitude Pacific & $\mathrm{ns}, 0.16$ & $1.07, \mathrm{~ns}$ & $-3.33,-2.63$ & $-4.40,-3.39$ \\
West tropical Pacific & $\mathrm{ns}, 0.29$ & $\mathrm{~ns}, \mathrm{~ns}$ & $\mathrm{~ns},-3.38$ & $-5.22,-4.22$ \\
East tropical Pacific & $\mathrm{ns},-0.57$ & $\mathrm{~ns},-2.43$ & $\mathrm{~ns}, \mathrm{~ns}$ & $\mathrm{~ns}, \mathrm{~ns}$ \\
North Pacific & $0.25,0.23$ & $\mathrm{~ns}, \mathrm{~ns}$ & $-4.25,-3.97$ & $-4.28,-5.96$ \\
South midlatitude Indian Ocean & $\mathrm{ns}, \mathrm{ns}$ & $\mathrm{ns}, \mathrm{ns}$ & $-4.01,-5.73$ & $-5.55,-5.23$ \\
Tropical Indian Ocean & $\mathrm{ns}, \mathrm{ns}$ & $3.04, \mathrm{~ns}$ & $-2.51,-6.43$ & $-5.55,-6.80$ \\
South midlatitude Atlantic & $0.40,0.14$ & $2.57,-0.31$ & $-3.65,-6.81$ & $-6.22,-6.50$ \\
Tropical Atlantic & $\mathrm{ns}, 0.12$ & $\mathrm{~ns}, \mathrm{~ns}$ & $-4.50,-7.22$ & $-4.78,-7.57$ \\
North midlatitude Atlantic & $0.32,0.54$ & $\mathrm{~ns}, \mathrm{~ns}$ & $-6.70,-6.05$ & $-7.03,-7.71$ \\
North high-latitude Atlantic and Arctic & $\mathrm{ns},-0.95$ & $\mathrm{~ns}, \mathrm{~ns}$ & $-12.33,-8.53$ & $-10.25,-6.74$ \\
\hline
\end{tabular}

Lovenduski et al. 2008; Russell et al. 2006). Furthermore, since the ACC is topographically constrained to between about $50^{\circ}$ and $55^{\circ} \mathrm{S}$, shifting the winds poleward yields closer alignment of the wind forcing with the ACC further enhancing Ekman pumping (Toggweiler and Russell 2008). Trends in both the strength and position of the Southern Hemisphere westerlies are evident in the CORE forcing (Figs. 8a,b). Indeed, net advection of
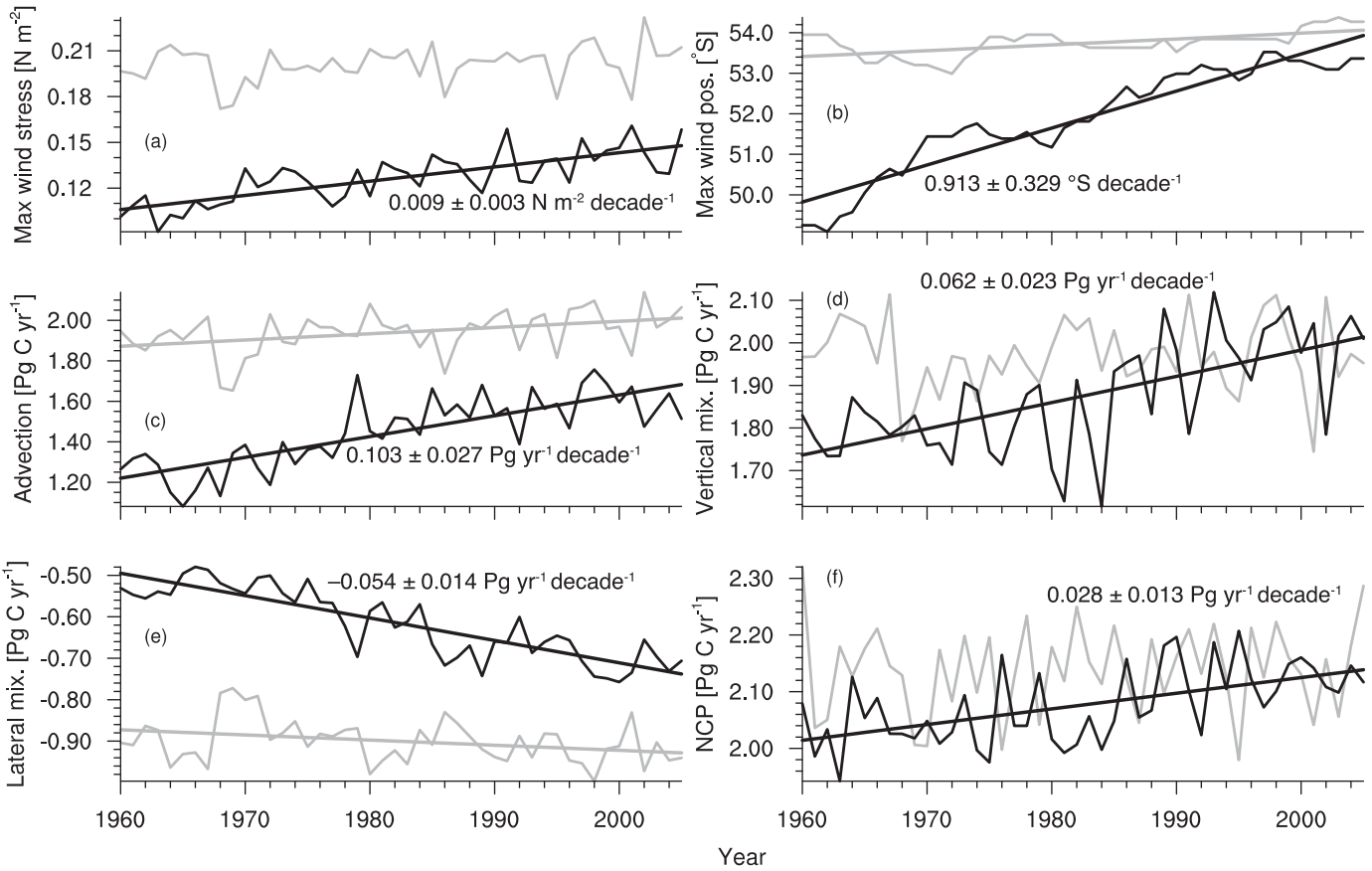

FIG. 8. Southern Ocean trends from the CORE-forced (black lines) and coupled (gray lines) $1850 \mathrm{CO}_{2}$ integrations for the period corresponding to 1960-2005. (a) Maximum zonal-mean zonal wind stress in the Southern Hemisphere. (b) Meridional position of maximum zonal-mean wind stress. Terms in the mass balance of DIC in the upper $100 \mathrm{~m}$ of the Southern Ocean (south of $44^{\circ} \mathrm{S}$ ): (c) net horizontal and vertical advection (at resolved scales), (d) vertical diffusion (parameterized mixing), (e) eddy-induced lateral mixing, and (f) net community production (biological consumption of DIC minus respiration or release of DIC). The data in (b) were smoothed with a 10-yr running mean to reduce year-to-year noise. Trend lines show regressions significant at the $95 \%$ level; the slope is noted in each panel. Coefficients of determination $\left(r^{2}\right)$ for the CORE regressions are (a) 0.593, (b) 0.897, (c) 0.630, (d) 0.421, (e) 0.743 , and (f) 0.319 . No significant trends were evident in the coupled model. 


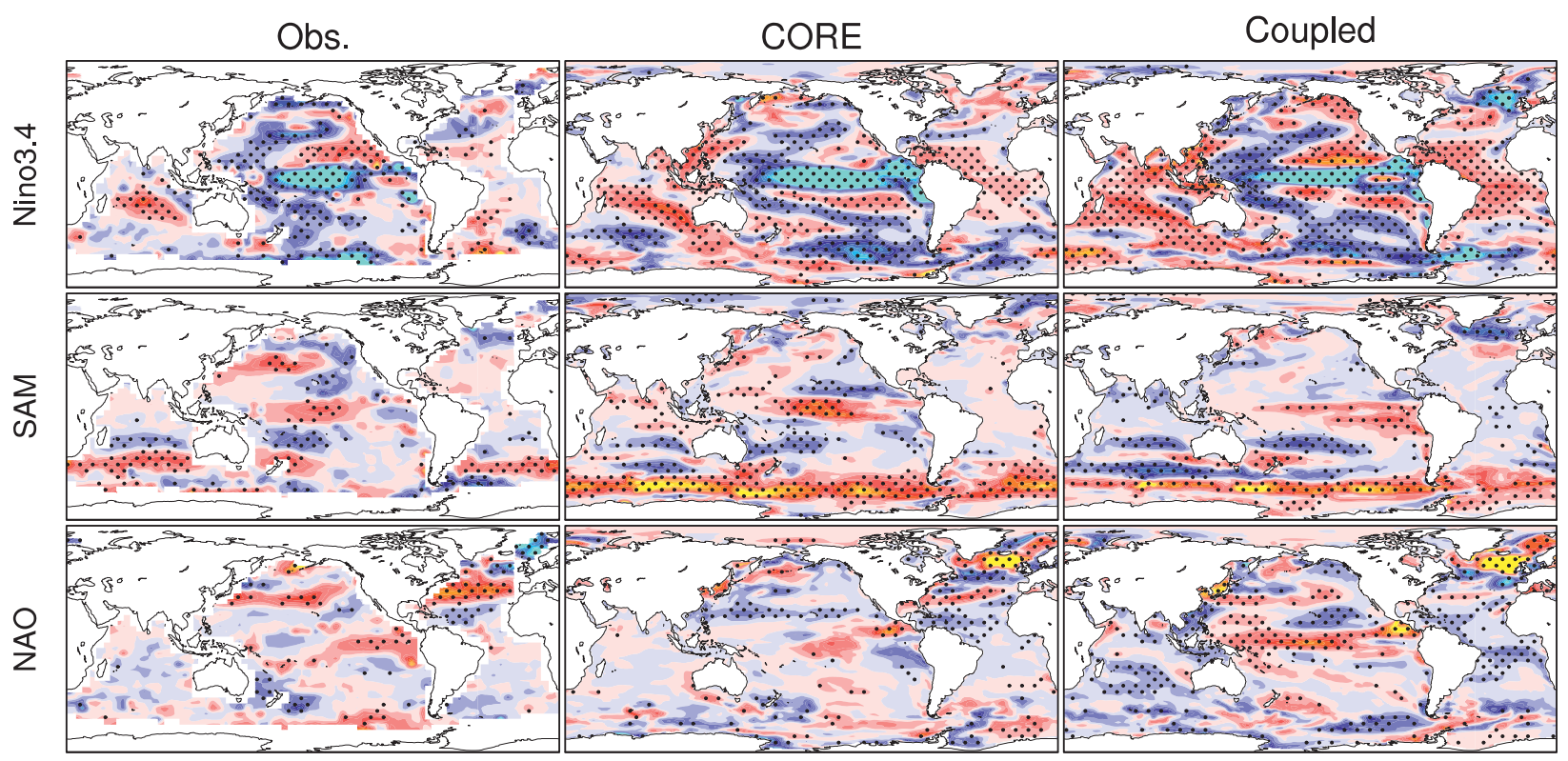

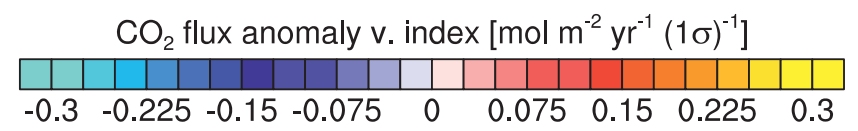

FIG. 9. Regression of sea-air $\mathrm{CO}_{2}$ flux anomalies vs the standardized (top) Niño-3.4 index, (middle) SAM, and (bottom) NAO. (left) Observationally based data of Park et al. (2010). (center) The ocean-ice hindcast. (right) The coupled model results. Stippling denotes significance at the $95 \%$ confidence limit.

DIC into the upper $100 \mathrm{~m}$ of the Southern Ocean increases between 1960 and 2005 in the CORE-forced integration (Fig. 8c), which is the dominant mechanism driving a positive trend in natural $\mathrm{CO}_{2}$ outgassing.
Notably, there are no significant trends in the zonalmean zonal wind stress or carbon budget components in the coupled model (Fig. 8). Some of the twentiethcentury CCSM4 ensemble members show stronger

TABLE 4. Mean spatially integrated and areal contemporary sea-air $\mathrm{CO}_{2}$ fluxes and variability ( $1 \sigma$ of annual mean) by region for the period 1990 and 2005. In each column, the first number is the Park et al. (2010) estimate, the last two numbers are CORE20C and CPLD20C, respectively. Note that the numbers reported here differ from those in Table 1 of Park et al. (2010) because of averaging over a different time period and exclusion of the Southern Ocean sea ice zone. "Na" denotes values that are not available.

\begin{tabular}{|c|c|c|c|c|c|}
\hline & $\begin{array}{c}\text { Mean } \\
\left(\mathrm{PgC} \mathrm{yr}^{-1}\right)\end{array}$ & $\begin{array}{l}\text { Variability } \\
\left(\mathrm{PgC} \mathrm{yr}^{-1}\right)\end{array}$ & $\begin{array}{c}\text { Mean } \\
\left(\mathrm{mol} \mathrm{m}^{-2} \mathrm{yr}^{-1}\right)\end{array}$ & $\begin{array}{c}\text { Variability } \\
\left(\mathrm{mol} \mathrm{m}^{-2} \mathrm{yr}^{-1}\right)\end{array}$ & $\begin{array}{c}\text { Area } \\
\left(10^{6} \mathrm{~km}^{2}\right)\end{array}$ \\
\hline Global $^{\text {b }}$ & $-1.15,-1.59,-1.55$ & $0.12,0.19,0.15$ & $-0.31,-0.40,-0.39$ & $0.03,0.05,0.04$ & $326.30,332.39$ \\
\hline Southern Ocean $<58^{\circ} \mathrm{S}$ & na, $-0.18,-0.28$ & na, $0.03,0.03$ & na, $-0.61,-0.96$ & na, $0.10,0.09$ & $23.86,24.31$ \\
\hline Southern Ocean $>58^{\circ} \mathrm{S}$ & $-0.26,-0.15,-0.17$ & $0.02,0.05,0.05$ & $-0.68,-0.33,-0.38$ & $0.05,0.12,0.10$ & $32.34,38.03$ \\
\hline South midlatitude Pacific & $-0.30,-0.36,-0.34$ & $0.02,0.02,0.02$ & $-0.64,-0.81,-0.75$ & $0.03,0.05,0.05$ & $38.91,37.61$ \\
\hline West tropical Pacific & $0.06,-0.12,-0.17$ & $0.04,0.07,0.03$ & $0.16,-0.30,-0.44$ & $0.10,0.17,0.08$ & $30.39,32.81$ \\
\hline East tropical Pacific & $0.53,0.65,0.75$ & $0.07,0.14,0.07$ & $1.30,1.58,1.81$ & $0.17,0.33,0.17$ & $33.59,34.57$ \\
\hline North Pacific & $-0.47,-0.56,-0.66$ & $0.02,0.02,0.03$ & $-0.99,-1.04,-1.22$ & $0.05,0.04,0.05$ & $39.98,45.03$ \\
\hline South midlatitude Indian Ocean & $-0.38,-0.34,-0.31$ & $0.01,0.02,0.03$ & $-1.16,-1.07,-0.95$ & $0.04,0.07,0.09$ & $27.10,26.73$ \\
\hline Tropical Indian Ocean & $0.12,-0.00,-0.01$ & $0.01,0.02,0.03$ & $0.38,-0.00,-0.04$ & $0.02,0.06,0.08$ & $25.26,30.85$ \\
\hline South midlatitude Atlantic & $-0.12,-0.17,-0.11$ & $0.01,0.01,0.01$ & $-0.54,-0.75,-0.50$ & $0.05,0.04,0.07$ & $19.43,18.82$ \\
\hline Tropical Atlantic & $0.11,0.09,0.07$ & $0.01,0.02,0.02$ & $0.45,0.32,0.23$ & $0.05,0.07,0.08$ & $21.13,24.21$ \\
\hline North midlatitude Atlar & $-0.20,-0.23,-0.16$ & $0.02,0.02,0.02$ & $-0.78,-0.84,-0.58$ & $0.06,0.08,0.06$ & $20.87,22.57$ \\
\hline North high-latitude Atlantic ${ }^{c}$ & $-0.23,-0.39,-0.38$ & $0.04,0.01,0.01$ & $-2.58,-1.99,-1.93$ & $0.42,0.06,0.07$ & $11.32,16.29$ \\
\hline
\end{tabular}

${ }^{a}$ The first number in this column is the Park et al. (2010) area, while the second is from CESM; they differ as a result of differing resolution.

${ }^{\mathrm{b}}$ Excluding area south of $60^{\circ} \mathrm{S}$ and Arctic above $80^{\circ} \mathrm{N}$.

${ }^{\mathrm{c}}<80^{\circ} \mathrm{N}$. 

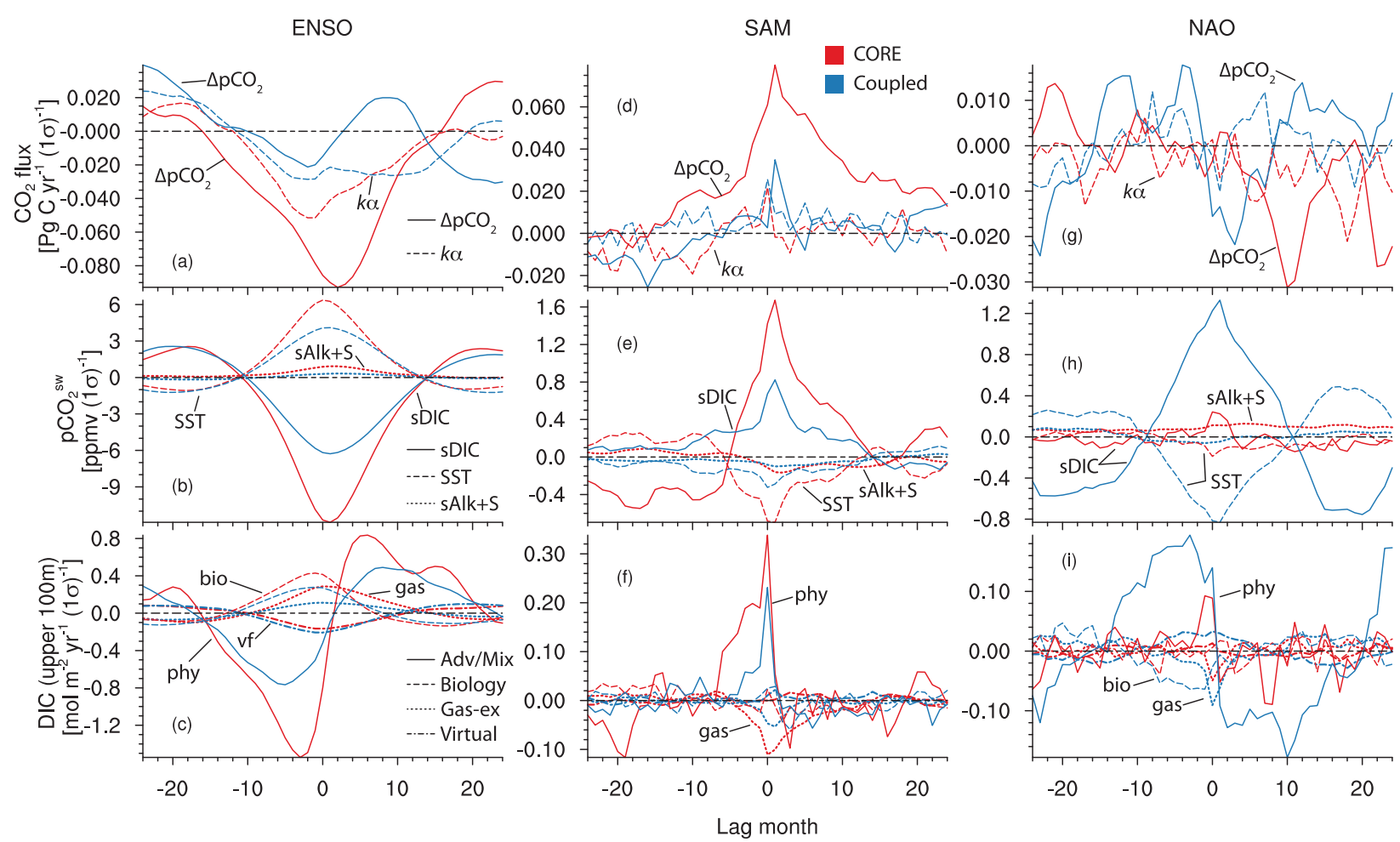

FIG. 10. Lagged regressions of linear Taylor series components of sea-air (top) $\mathrm{CO}_{2}$ flux, (middle) surface ocean $p \mathrm{CO}_{2}$, and (bottom) upper ocean dissolved inorganic carbon inventory against climate indices: (left) Niño-3.4, (center) SAM, and (right) NAO. Red lines show results from the CORE-forced integrations; blue show coupled results. The legend for each row is shown in the plot on the far left. See text for description of various terms.

trends in zonal-mean zonal wind but none as strong as the reanalysis-based CORE data (Weijer et al. 2012).

Given that enhanced wind-driven upwelling drives the positive trend in sea-air flux in the CORE-forced integration, one might expect greater outgassing in the coupled model-mean state since the coupled model has greater wind stress over the entire 1960-2005 period (Fig. 8a). Outgassing of natural $\mathrm{CO}_{2}$ is weaker in the coupled model, however, which is due to a different DIC distribution: Southern Ocean surface $s$ DIC is greater and the vertical gradient in $s \mathrm{DIC}$ is stronger in the CORE-forced run relative to the coupled model (Fig. S2 of the supplementary material). Notably, both model configurations underestimate the vertical gradient in $s$ DIC compared to the observationally based climatology, with markedly different structure in the $s$ DIC profile between about 300 and $1200 \mathrm{~m}$ (Fig. S2).

Transport of DIC by the Eulerian-mean circulation and turbulent diffusion across $100 \mathrm{~m}$ are the dominant components causing DIC to increase in Southern Ocean surface waters in CORE20C (Figs. 8c,d). Notably, eddyinduced lateral advection and isopycnal mixing (i.e., parameterized mesoscale mixing) work to oppose resolved advection; this effect becomes more negative as winds increase (Fig. 8e). This behavior is consistent with theory, which suggests that the eddy-induced overturning should compensate increases in the Eulerian-mean overturning (Marshall and Radko 2003). The degree to which compensation should occur is uncertain, however, and may be too weak in the model. Nevertheless, the variable eddy-induced advection coefficient permits eddy-induced overturning to accelerate in opposition to the mean flow and partially compensate for increases in wind-driven overturning (Lovenduski et al. 2013).

The final term in the Southern Ocean DIC budget is export production (Fig. 8f), which is a net sink for DIC in the upper ocean. The magnitude of this sink increases in the CORE-forced runs as greater rates of upwelling supply additional nutrients to the surface layer.

\section{f. Interannual variability of sea-air fluxes}

In this section, we examine the mechanisms forcing climate-driven variability in $\mathrm{CO}_{2}$ fluxes on interannual time scales. Our analysis is focused on three dominant modes of climate variability: ENSO, SAM, and NAO, which have a strong influence over ocean physical dynamics and sea-air $\mathrm{CO}_{2}$ flux. A key question is whether the coupled model can reproduce the biogeochemical effects related to these modes of variability. 


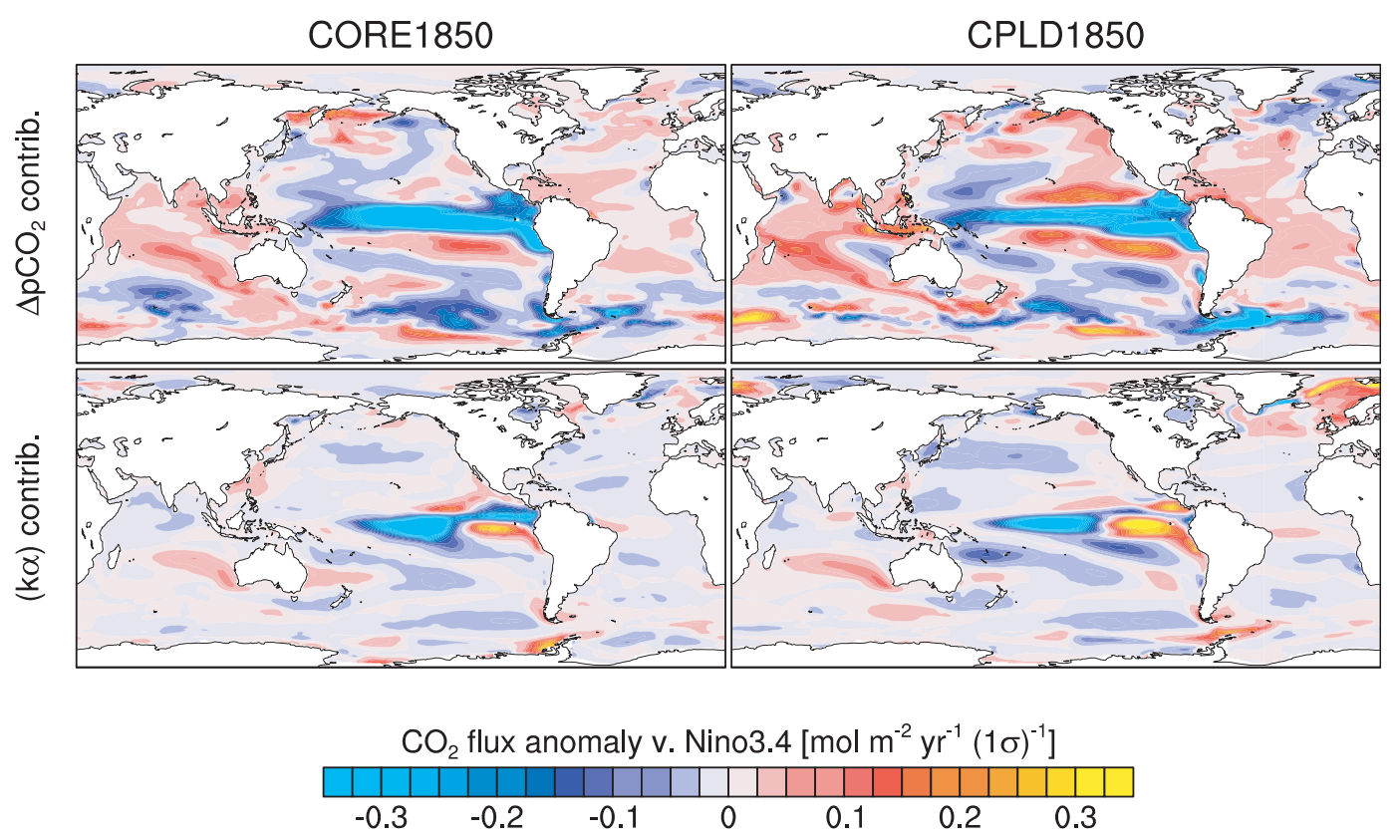

FIG. 11. Regression of sea-air $\mathrm{CO}_{2}$ flux anomaly components from the (left) ocean-ice hindcast and (right) coupled model vs the standardized Niño-3.4 index (Trenberth 1997).

ENSO is the dominant mode of climate variability driving interannual variability in globally integrated sea-air $\mathrm{CO}_{2}$ fluxes. During an El Niño event, upwelling of DIC-rich waters in the central and eastern equatorial Pacific is diminished as a result of weakened trade winds. This reduces outgassing locally (Feely et al. 1999; Chavez et al. 1999); furthermore, physical mechanisms in the ocean and atmosphere propagate ENSO-related variability over much of the globe (Wang and Schimel 2003).

In CESM1, a positive ENSO state is characterized by diminished outgassing (order $-0.3 \mathrm{~mol} \mathrm{~m}^{-2} \mathrm{yr}^{-1}$ ) in the central equatorial Pacific, a somewhat weaker response of the same sign in the southern Pacific and Atlantic basins and anomalous outgassing over much of the remaining tropics (Fig. 9). This pattern has some similarity to that present in the observationally based reconstruction of Park et al. (2010); however, the spatial extent of anomalous uptake in the central equatorial Pacific is greater in the model, and the degree of anomalous outgassing elsewhere in the tropics is also greater, particularly in the coupled configuration. The counteracting effect of anomalous outgassing beyond the eastern equatorial Pacific weakens the global ENSO-related variability in the coupled model (Fig. 9). Global sea-air fluxes in the hindcast simulation have greater variability than is evident in the Park et al. (2010; Table 4) reconstruction, which may be due to the coarser resolution of the observational climatology (note that Table 4 presents contemporary sea-air $\mathrm{CO}_{2}$ fluxes).
In the CORE-forced integration, changes in $\Delta p \mathrm{CO}_{2}$ dominate the $\mathrm{CO}_{2}$ flux response to ENSO variability (solid lines, Fig. 10a). This effect is about double that resulting from reductions in the piston velocity (red dashed line, Fig. 10a), although the influence of piston velocity anomalies are comparable to $\Delta p \mathrm{CO}_{2}$ in the central Pacific (Fig. 11). In the coupled model, by contrast, the two components of the flux response are quite similar (at zero lag), and the combined overall flux response (blue lines, Fig. 10a) is weaker and out of phase with the CORE results.

The $p \mathrm{CO}_{2}^{\mathrm{sw}}$ response to ENSO can be further decomposed into driving mechanisms. In the equatorial Pacific, there is a competition between warmer SSTs driving $p \mathrm{CO}_{2}^{\mathrm{sw}}$ up and reduced DIC driving it down (Fig. 12). The SST and DIC effects on $p \mathrm{CO}_{2}^{\mathrm{sw}}$ are both greater in magnitude in the CORE-forced run than in the coupled model; the DIC effect dominates in both configurations but to a greater extent in the hindcast (Fig. 10b). Physically mediated DIC fluxes (vertical advection and mixing) are the primary terms controlling ENSO-related variability (solid lines, Fig. 10c). The coupled model response is weaker because of compensating increases in upwelling - particularly in the eastern Indian Ocean, as well as the North and South Pacificthat are more pronounced than in the CORE-forced run (Fig. 13).

In addition to ENSO, the SAM also strongly influences sea-air fluxes at the global scale. A positive phase of the SAM is associated with a poleward shift and 

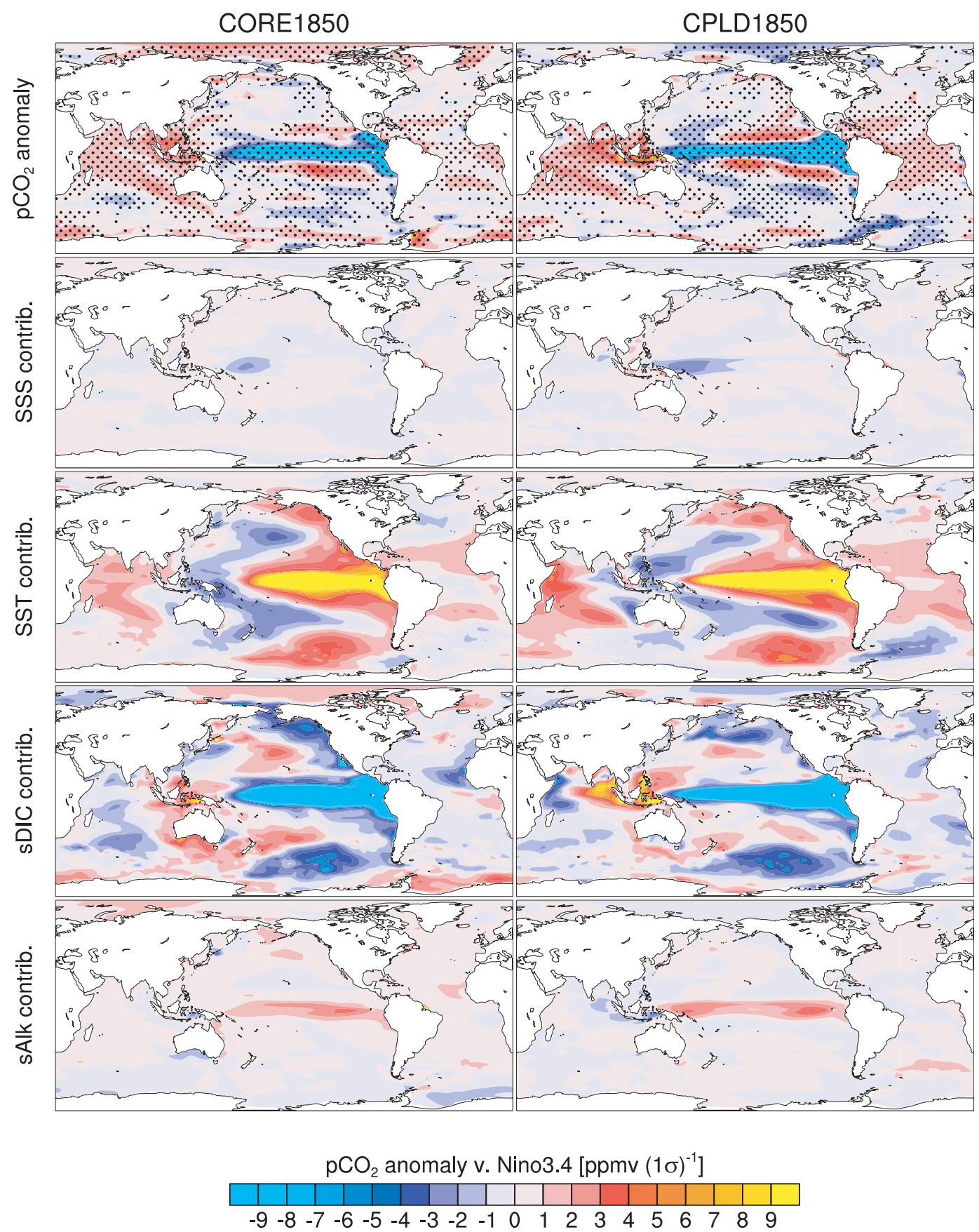

FIG. 12. Regression of surface ocean $p \mathrm{CO}_{2}$ anomalies and components from the (left) ocean-ice hindcast and (right) coupled model vs the standardized Niño-3.4 index (Trenberth 1997). (top) Stippling denotes significance at the $95 \%$ confidence limit; no significance metric is shown on the plots for the components.

intensification of the Southern Hemisphere westerly wind field (Thompson and Solomon 2002), which leads to enhanced DIC upwelling and $\mathrm{CO}_{2}$ outgassing (Lovenduski et al. 2007; Wang and Moore 2012). Similar to the case with ENSO, the coupled model predicts an overall spatial structure (Fig. 9) and temporal evolution (Fig. 10d) of SAM-related $\mathrm{CO}_{2}$ flux anomalies that is similar to the CORE-forced integration; however, the magnitude of the globally integrated $\mathrm{CO}_{2}$ flux response is weaker. The spatial pattern of the SAM $\mathrm{CO}_{2}$ flux response in the model bears some similarity to the observational reconstructions in the central Pacific, particularly in the 

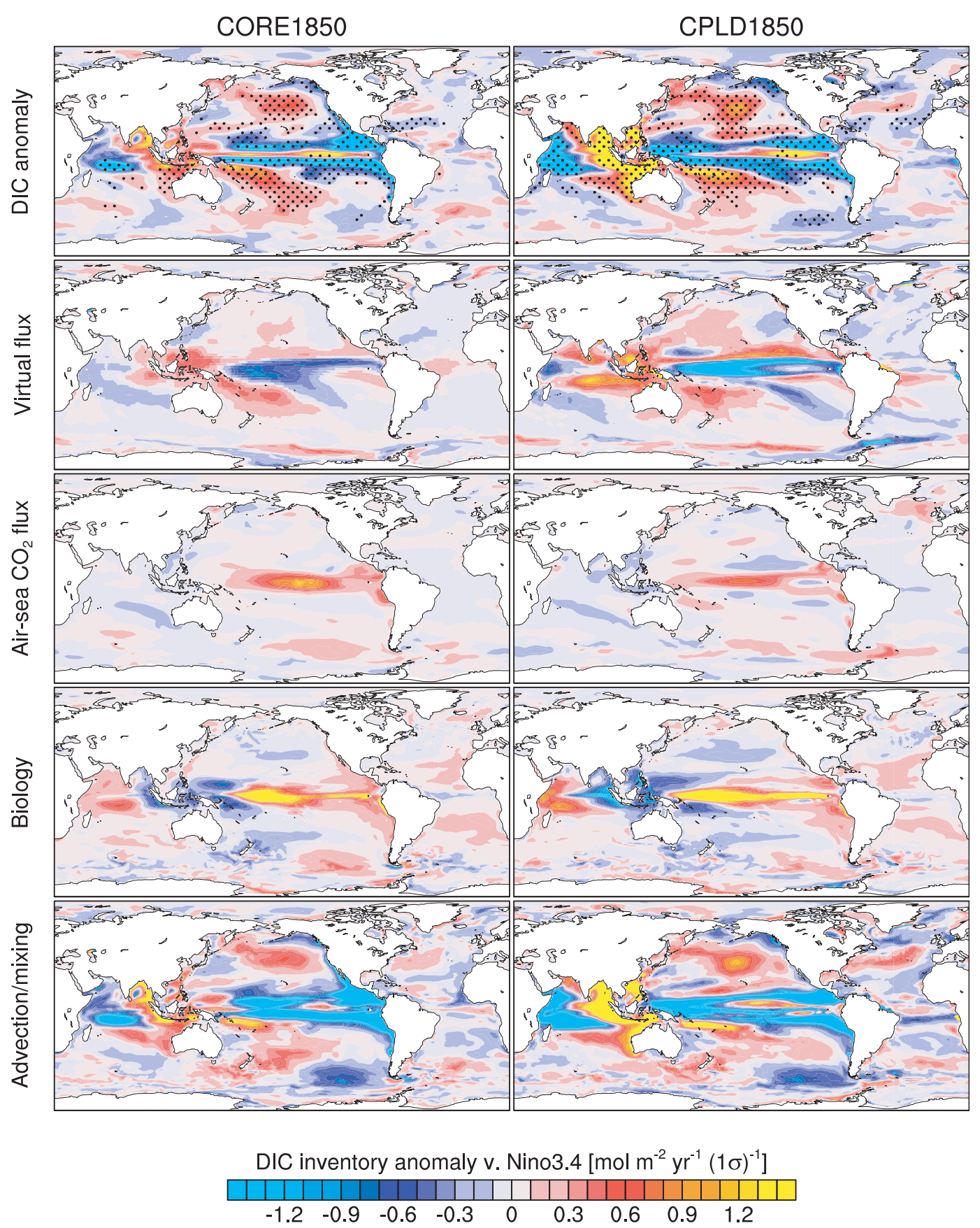

FIG. 13. Regression of upper-100-m DIC inventory anomalies and components from the (left) ocean-ice hindcast and (right) coupled model vs the standardized Niño-3.4 index (Trenberth 1997). (top) Stippling denotes significance at the $95 \%$ confidence limit; no significance metric is shown on the plots for the components.

CORE-forced integration, but is markedly different in the Southern Ocean (Fig. 9). The SAM-related $p \mathrm{CO}_{2}^{\mathrm{sw}}$ response is dominated by DIC anomalies (solid line, Fig. 10e) and driven by anomalous advection and mixing of DIC into the surface ocean (solid line, Fig. 10f). Reduced variability in the coupled model may be related in part to the smaller vertical $s$ DIC gradient in the
Southern Ocean (Fig. S2). In the CORE-forced integration, La Niña-like patterns in the equatorial Pacific are associated with the SAM (Fig. 9): cooler SSTs depress $p \mathrm{CO}_{2}^{\mathrm{sw}}$, while enhanced upwelling of DIC drives positive $p \mathrm{CO}_{2}^{\mathrm{sw}}$ anomalies and net outgassing (Figs. S3S5 of the supplementary material). Aspects of this spatial pattern are evident in the Park et al. (2010) observations; 

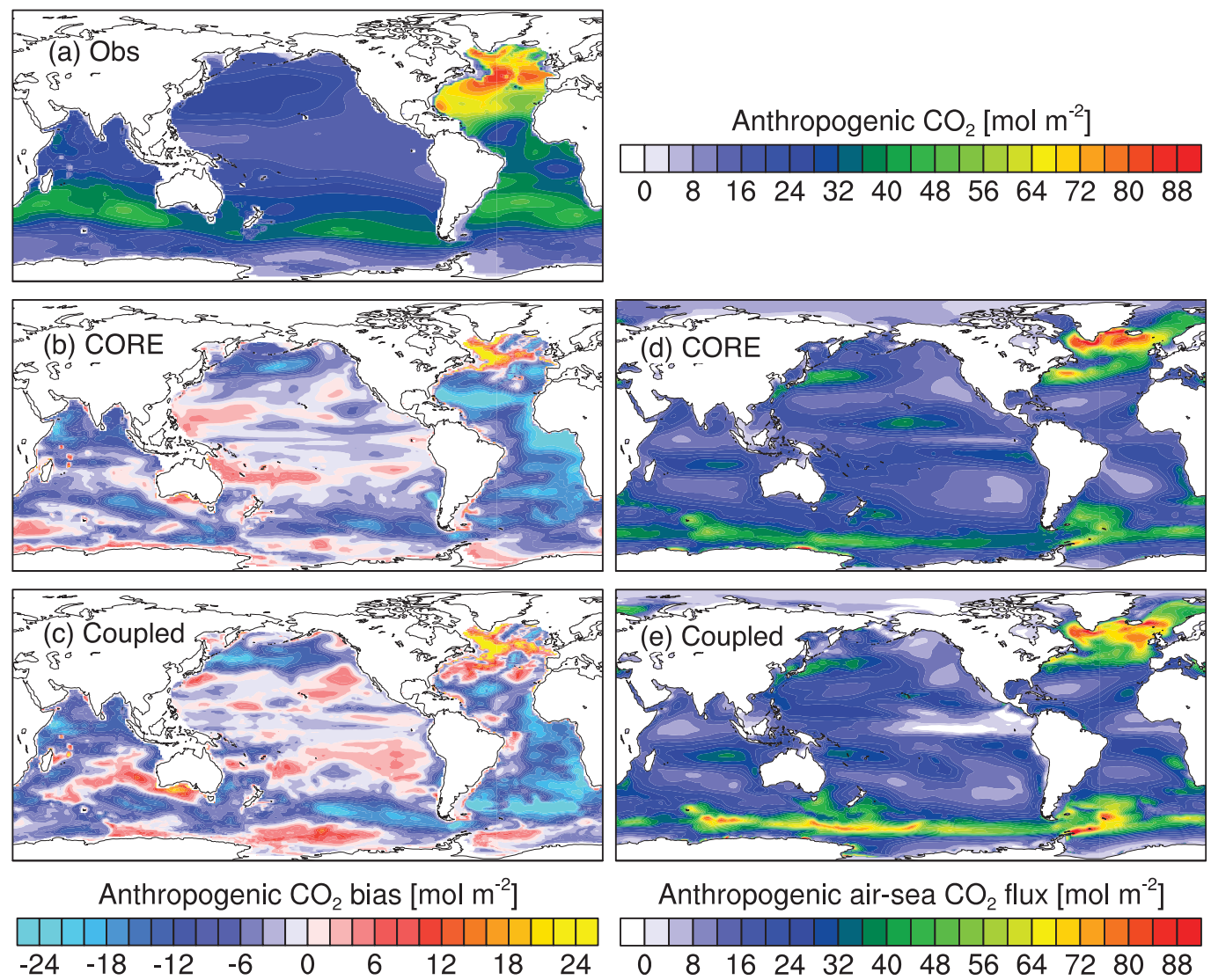

FIG. 14. Column inventory of anthropogenic $\mathrm{CO}_{2}\left(\mathrm{C}_{\text {ant }}\right)$ from (a) GLODAP (color bar, top right). Model biases in $\mathrm{C}_{\text {ant }}$ inventory for (b) CORE20C and (c) CPLD20C (color bar, bottom left). Air-sea flux of $\mathrm{C}_{\text {ant }}$ integrated over 1850-1995 in (d) CORE20C and (e) CPLD20C (note: positive equals uptake in this case).

a notable difference between these and the model, however, is that anomalous SAM-related outgassing is shifted equatorward in the observations (Fig. 9). Since Park et al. (2010) did not provide data poleward of about $60^{\circ} \mathrm{S}$, these data cannot be used to evaluate the model in this region.

While the NAO has local flux anomalies comparable in magnitude to those induced by ENSO and SAM (Fig. 9), its impact on globally integrated sea-air $\mathrm{CO}_{2}$ fluxes is weaker (Fig. 10g). In the Park et al. (2010) observational dataset, the NAO is associated with weak anomalous $\mathrm{CO}_{2}$ uptake in the tropical Atlantic, outgassing in the subtropics through the midlatitudes, and $\mathrm{CO}_{2}$ uptake poleward (Fig. 9). This pattern is not well reproduced by the models (Fig. 9), in which anomalous vertical advection and mixing, leading to positive DIC anomalies, drive outgassing in the high-latitude North Atlantic (Figs. S6-S8 of the supplementary material) where the observationally based estimates suggest anomalous uptake should occur. The NAO pattern in the North Atlantic is similar between the models; however, the behavior beyond this region is different (Figs. S6-S8). The most pronounced differences occur in the eastern Pacific, where the coupled model displays a La Niña-like pattern associated with the NAO (Figs. S6-S8).

\section{g. Carbon inventories}

Globally, the total oceanic $\mathrm{C}_{\mathrm{ant}}$ inventory in both CESM model configurations is too low relative to GLODAP (Table 2). Much of this discrepancy is a result of biases originating in the Southern Ocean; in particular, $\mathrm{C}_{\mathrm{ant}}$ concentrations are too low in what should be northward-flowing Antarctic Intermediate Water (AAIW; $\sigma_{\theta} \approx 27.3$; Fig. 15 ). Column inventories of $\mathrm{C}_{\mathrm{ant}}$ that are too low at midlatitudes (Fig. 14) are attributable to negative biases at intermediate depths $(200-1000 \mathrm{~m}$; Fig. 15). Weak Southern Ocean uptake was also a feature of prior model versions (CCSM3; Thornton et al. 2009; Wang et al. 2012). Notably, $C_{a n t}$ distributions in the CORE-forced and coupled configurations are similarly biased, in spite of much different winds.

Anthropogenic $\mathrm{CO}_{2}$ distributions in the Atlantic basin are marked by positive biases in the region of North Atlantic Deep Water (NADW) formation and negative biases over much of the remaining basin (Figs. 14b,c). 


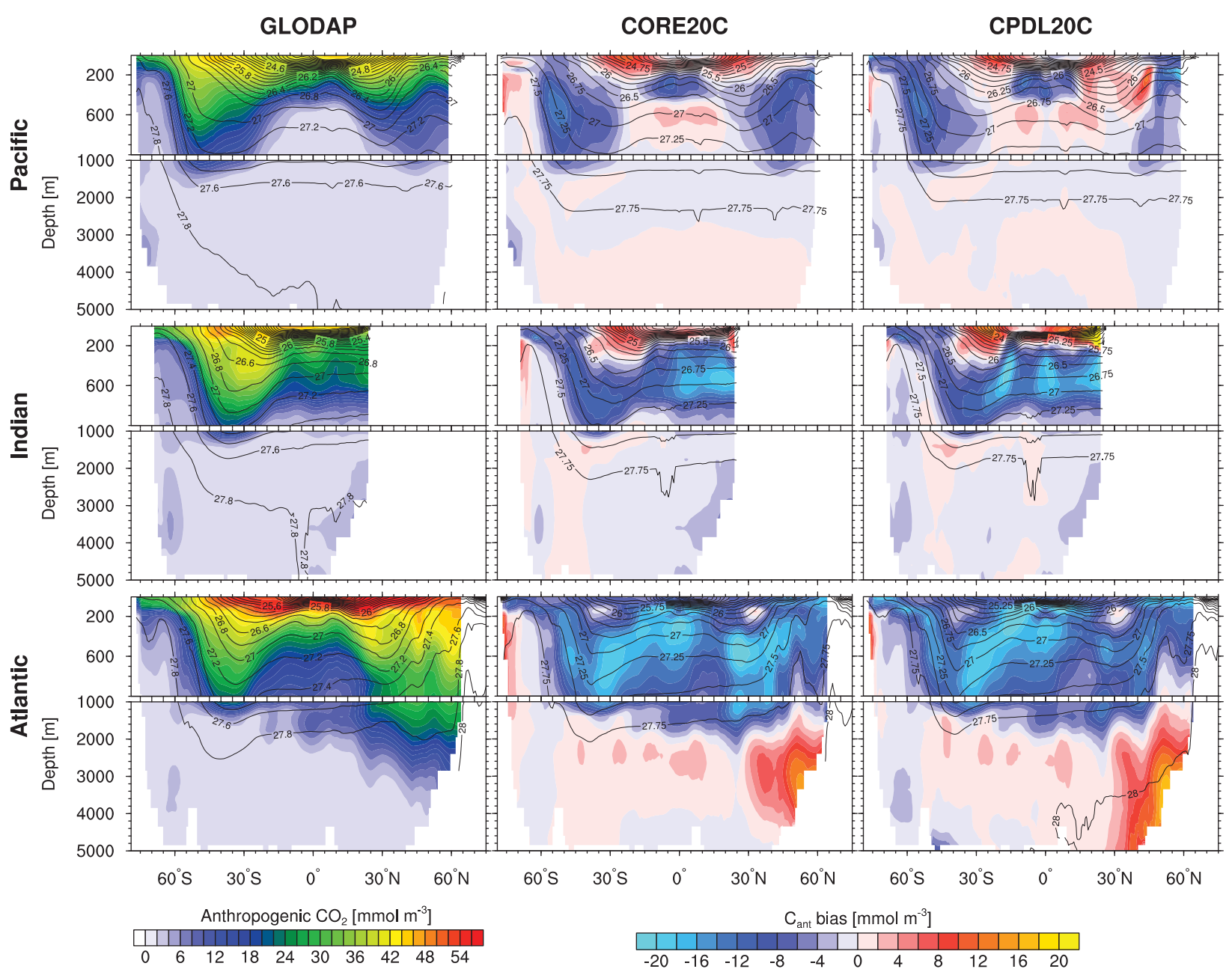

FIG. 15. Zonal-mean anthropogenic $\mathrm{CO}_{2}$ by ocean basin from (left) GLODAP, and model biases for (center) CORE20C and (right) CPLD20C. Contour lines show potential density surfaces.

Both model configurations display higher $\mathrm{C}_{\mathrm{ant}}$ concentrations at depth in the North Atlantic than is apparent in the GLODAP climatology. This pattern marks a significant change relative to previous versions of CESM (i.e., CCSM3), in which deep convection in the North Atlantic was displaced too far south, and $\mathrm{C}_{\mathrm{ant}}$ uptake in NADW was too weak (Thornton et al. 2009; Wang et al. 2012). Changes in North Atlantic uptake dynamics from CCSM3 are explained in part by the new Nordic sea overflow parameterization implemented in CCSM4, which represents unresolved density-driven flows through the Denmark Strait and Faroe Bank Channel, improving the simulation of NADW formation (Danabasoglu et al. 2010, 2012). Poor representation of AAIW contributes to negative biases in the southern part of the Atlantic basin; however, more detailed analysis is required to pinpoint the circulation features contributing to the basinwide bias patterns.
Finally, substantial low biases in the $\mathrm{C}_{\mathrm{ant}}$ inventories are evident in the North Pacific in both model configurations (Figs. 14b,c). Mode and intermediate water formation in the North Pacific regulate the transfer of $\mathrm{CO}_{2}$ into the ocean interior (Sabine et al. 2004). The physical processes controlling these water mass transformations are complex (e.g., Nakamura et al. 2006) and not well represented by CESM.

Collectively, the patterns of $\mathrm{C}_{\text {ant }}$ biases emphasize the importance of physical representations controlling the model's circulation fields (Doney et al. 2004). To emphasize this point, we examine chlorofluorocarbons distributions. While carbon uptake involves both physical and biological processes, oceanic CFC uptake is simply controlled by thermodynamic equilibriums and therefore provides a better indication of physical transport. By examining the partial pressure of CFCs $(p C F C)$ rather than concentrations, the effect of model temperature 


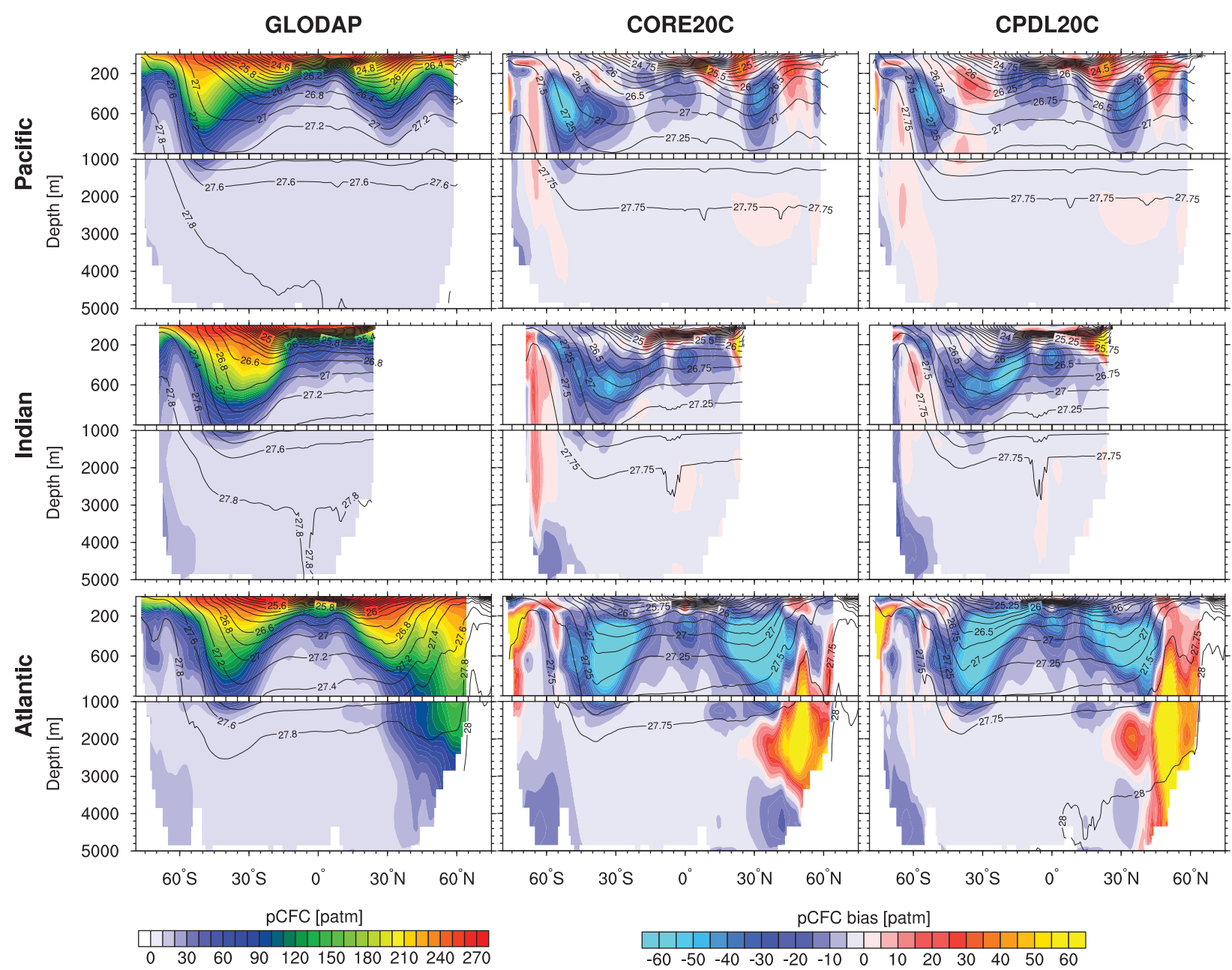

FIG. 16. Zonal-mean partial pressure of CFC-11 ( $p$ CFC-11) by ocean basin from (left) GLODAP and model biases for (center) CORE20C and (right) CPLD20C. Contour lines show potential density surfaces.

biases on CFC distributions is minimized. Examination of zonal-mean biases in $p$ CFC-11 (Fig. 16) confirms the inferences regarding circulation biases gleaned from $\mathrm{C}_{\mathrm{ant}}$ distributions: mode and intermediate water formation in the Southern Ocean is too weak (Weijer et al. 2012); deep convection locally near Antarctica and in the North Atlantic appears too vigorous. We note that small deep-ocean positive $\mathrm{C}_{\mathrm{ant}}$ biases are ubiquitous in the model (Fig. 15) and greater in magnitude than comparable biases in $p$ CFC-11 at depth (Fig. 16). Some portion of this pattern may be attributable to systematic biases in $\Delta C^{*}$-derived $C_{a n t}$, which underestimates concentrations at depth (Matsumoto and Gruber 2005; Wang et al. 2012).

The processes affecting mode and intermediate water formation include atmospheric fluxes of buoyancy and momentum. While there is considerable uncertainty in these forcings over the Southern Ocean (e.g., Cerovecki et al. 2011), the fact that the CORE-forced and coupled integrations have similar biases implicates inadequate process representation internal to the ocean model. Indeed, Southern Ocean mixed layer depths are severely too shallow by $30-50 \mathrm{~m}$ in the ACC during summer and $100-400 \mathrm{~m}$ in winter in both CORE20C and CPLD20C (Danabasoglu et al. 2012; Moore et al. 2013). Mixed layer biases result in weakened uptake, in part through an interaction with the lateral eddymixing parameterizations, in which the vertical structure of mixing coefficients depends on boundary layer depth.

\section{Summary and conclusions}

We have presented an analysis documenting the representation of regional and temporal variability in airsea fluxes and ocean carbon uptake and storage in two 
configurations of CESM1(BGC). Overall, the model captures much of the important spatial and seasonal patterns in $p \mathrm{CO}_{2}^{\mathrm{sw}}$, leading to a generally realistic representation of sea-air fluxes. Low surface alkalinity is an important bias in the model, which contributes to underestimation of oceanic $\mathrm{CO}_{2}$ uptake associated with a perturbation to atmospheric $\mathrm{CO}_{2}$.

Modeled temporal trends in surface ocean $p \mathrm{CO}_{2}$ did not deviate radically from trends in $p \mathrm{CO}_{2}^{\text {atm }}$ over the period examined (1981-2005). During this period, $p \mathrm{CO}_{2}^{\mathrm{atm}}$ increased at $1.59 \mathrm{ppm} \mathrm{yr}^{-1}$, while global-mean $p \mathrm{CO}_{2}^{\mathrm{sw}}$ in both model configurations increased at slightly lower rates: 1.56 (CORE) and $1.52 \mathrm{ppm} \mathrm{yr}^{-1}$ (coupled). The model results are consistent with observations in this regard; regional discrepancies from the atmospheric trend are evident, but as a whole the surface ocean tracks the atmosphere. It is important to note that the coupled model's climate sensitivity over the twentieth century leads to surface ocean warming in excess of that observed; because of greater warming in the coupled simulation, relative to the CORE-forced run, a greater proportion of the trend in $p \mathrm{CO}_{2}^{\mathrm{sw}}$ was due to temperature in the coupled model.

A key question is whether the CESM coupled model can accurately represent the impact of climate variability on carbon cycle dynamics. We presented an analysis of the mechanisms driving interannual variability in sea-air fluxes. The impact of climate variability on sea-air fluxes is similar between the model and observational estimates. Variability in the coupled model was weak, relative to that simulated by the CORE-forced model. The basic structure of the coupled model's response to key climate modes was similar to observational metrics and the CORE-forced integration; however, the response to variability in the coupled model differed in its regional detail.

Uptake and storage of $\mathrm{C}_{\mathrm{ant}}$ in the Southern Ocean remains a problematic feature of coarse resolution global carbon cycle simulations. In particular, the ventilation and formation of intermediate and mode waters in the Southern Ocean is not well captured by the model. A related issue is the substantial Southern Ocean mixed layer biases, which are too shallow by $30-50 \mathrm{~m}$ in the ACC during summer and by 100-400 $\mathrm{m}$ during winter. Mixed layer depths interact with the processes controlling ventilation. For instance, in the model the boundary layer depth sets the near-surface region over which the eddy-mixing coefficient is the maximum. Substantial improvements in the physical parameterizations controlling mixing and overturning in the model are necessary to improve the representation of ventilation. The current CESM configuration can be expected to continue to underestimate $\mathrm{C}_{\mathrm{ant}}$ uptake under twenty-first-century scenarios.
Acknowledgments. The CESM project is supported by the National Science Foundation and the Office of Science (BER) of the U.S. Department of Energy. Computing resources were provided by the Climate Simulation Laboratory at NCAR's Computational and Information Systems Laboratory (CISL), sponsored by the National Science Foundation and other agencies. This research was enabled by CISL compute and storage resources. Bluefire, a 4,064-processor IBM Power6 resource with a peak of 77 teraflops provided more than 7.5 million computing hours, the GLADE high-speed disk resources provided 0.4 petabytes of dedicated disk, and CISL's 12-PB HPSS archive provided over 1 petabyte of storage in support of this research project. SCD acknowledges support of Collaborative Research: Improved Regional and Decadal Predictions of the Carbon Cycle (NSF AGS1048827).

\section{REFERENCES}

Armstrong, R., C. Lee, J. Hedges, S. Honjo, and S. Wakeham, 2002: A new, mechanistic model for organic carbon fluxes in the ocean based on the quantitative association of POC with ballast minerals. Deep-Sea Res. II, 49, 219-236, doi:10.1016/ S0967-0645(01)00101-1.

Arrigo, K. R., G. van Dijken, and S. Bushinsky, 2008a: Primary production in the Southern Ocean, 1997-2006. J. Geophys. Res., 113, C08004, doi:10.1029/2007JC004551.

,-- , and M. C. Long, 2008b: Coastal Southern Ocean: A strong anthropogenic $\mathrm{CO}_{2}$ sink. Geophys. Res. Lett., 35, L21602, doi:10.1029/2008GL035624.

Cerovecki, I., L. Talley, and M. Mazloff, 2011: A comparison of Southern Ocean air-sea buoyancy flux from an ocean state estimate with five other products. J. Climate, 24, 6283-6306.

Chavez, F. P., P. G. Strutton, G. E. Friederich, R. A. Feely, G. C. Feldman, D. G. Foley, and M. J. McPhaden, 1999: Biological and chemical response of the equatorial Pacific Ocean to the 1997-98 El Niño. Science, 286, 2126-2131, doi:10.1126/ science.286.5447.2126.

Crutzen, P., 2006: The "anthropocene.” Earth System Science in the Anthropocene, E. Ehlers and T. Krafft, Eds., Springer Berlin Heidelberg, 13-18.

Danabasoglu, G., and J. Marshall, 2007: Effects of vertical variations of thickness diffusivity in an ocean general circulation model. Ocean Modell., 18, 122-141, doi:10.1016/ j.ocemod.2007.03.006.

_ W. W. Large, and B. P. Briegleb, 2010: Climate impacts of parameterized Nordic sea overflows. J. Geophys. Res., 115, C11005, doi:10.1029/2010JC006243.

_ S. Bates, B. P. Briegleb, S. R. Jayne, M. Jochum, W. G. Large, S. Peacock, and S. G. Yeager, 2012: The CCSM4 ocean component. J. Climate, 25, 1361-1389.

Dickson, A. G., and C. Goyet, Eds., 1994: Handbook of methods for the analysis of the various parameters of the carbon dioxide system in sea water: Version 2. Oak Ridge National Lab Tech. Rep. ORNL/CDIAC-74, 187 pp.

Doney, S. C., D. M. Glover, S. J. McCue, and M. Fuentes, 2003: Mesoscale variability of Sea-Viewing Wide Field-of-View Sensor (SeaWiFS) satellite ocean color: Global patterns 
and spatial scales. J. Geophys. Res., 108, 3024, doi:10.1029/ 2001JC000843.

— , and Coauthors, 2004: Evaluating global ocean carbon models: The importance of realistic physics. Global Biogeochem. Cycles, 18, GB3017, doi:10.1029/2003GB002150.

_ - K. Lindsay, I. Fung, and J. John, 2006: Natural variability in a stable, 1000-yr global coupled climate-carbon cycle simulation. J. Climate, 19, 3033-3054.

_, S. Yeager, G. Danabasoglu, W. G. Large, and J. C. McWilliams, 2007: Mechanisms governing interannual variability of upperocean temperature in a global ocean hindcast simulation. J. Phys. Oceanogr., 37, 1918-1938.

— I. Lima, R. Feely, D. Glover, K. Lindsay, N. Mahowald, J. Moore, and R. Wanninkhof, 2009a: Mechanisms governing interannual variability in upper-ocean inorganic carbon system and air-sea $\mathrm{CO}_{2}$ fluxes: Physical climate and atmospheric dust. Deep-Sea Res. II, 56, 640-655, doi:10.1016/j.dsr2.2008.12.006.

__ , and Coauthors, 2009b: Skill metrics for confronting global upper ocean ecosystem-biogeochemistry models against field and remote sensing data. J. Mar. Syst., 76, 95-112, doi:10.1016/ j.jmarsys.2008.05.015.

Farneti, R., and P. R. Gent, 2011: The effects of the eddyinduced advection coefficient in a coarse-resolution coupled climate model. Ocean Modell., 39, 135-145, doi:10.1016/ j.ocemod.2011.02.005.

Feely, R. A., R. Wanninkhof, T. Takahashi, and P. Tans, 1999: Influence of $\mathrm{El} N$ Niño on the equatorial Pacific contribution to atmospheric $\mathrm{CO}_{2}$ accumulation. Nature, 398, 597-601, doi:10.1038/ 19273.

Fox-Kemper, B., and Coauthors, 2010: Parameterization of mixed layer eddies. III: Implementation and impact in global ocean climate simulations. Ocean Modell., 39, 61-78, doi:10.1016/ j.ocemod.2010.09.002.

Friedlingstein, P., and Coauthors, 2006: Climate-carbon cycle feedback analysis: Results from the $\mathrm{C}^{4} \mathrm{MIP}$ model intercomparison. J. Climate, 19, 3337-3353.

Fung, I. Y., S. C. Doney, K. Lindsay, and J. John, 2005: Evolution of carbon sinks in a changing climate. Proc. Natl. Acad. Sci. USA, 102, 11 201-11206, doi:10.1073/pnas.0504949102.

Garcia, H. E., R. A. Locarnini, T. P. Boyer, and J. I. Antonov, 2006: Nutrients (phosphate, nitrate, silicate). Vol. 4, World Ocean Atlas 2005, NOAA Atlas NESDIS 64, 396 pp.

Gent, P. R., 2011: The Gent-McWilliams parameterization: 20/20 hindsight. Ocean Modell., 39, 2-9, doi:10.1016/ j.ocemod.2010.08.002.

—_ and J. McWilliams, 1990: Isopycnal mixing in ocean circulation models. J. Phys. Oceanogr., 20, 150-155.

—_, and G. Danabasoglu, 2011: Response to increasing Southern Hemisphere winds in CCSM4. J. Climate, 24, 4992-4998.

_ , and Coauthors, 2011: The Community Climate System Model version 4. J. Climate, 24, 4973-4991.

Griffies, S., and Coauthors, 2009: Coordinated Ocean-Ice Reference Experiments (COREs). Ocean Modell., 26, 1-46, doi:10.1016/j.ocemod.2008.08.007.

Gruber, N., J. L. Sarmiento, and T. F. Stocker, 1996: An improved method for detecting anthropogenic $\mathrm{CO}_{2}$ in the oceans. Global Biogeochem. Cycles, 10, 809-837, doi:10.1029/ 96GB01608.

— atmospheric $\mathrm{CO}_{2}$. Global Biogeochem. Cycles, 23, GB1005, doi:10.1029/2008GB003349.

Hunke, E., and W. Lipscomb, 2008: CICE: The Los Alamos sea ice model documentation and software user's manual, version 4.0
Los Alamos National Laboratory Tech. Rep. LA-CC-06-012, $76 \mathrm{pp}$.

Hurrell, J. W., 1995: Decadal trends in the North Atlantic Oscillation: Regional temperatures and precipitation. Science, 269, 676-679, doi:10.1126/science.269.5224.676.

_ J. J. Hack, D. Shea, J. M. Caron, and J. Rosinski, 2008: A new sea surface temperature and sea ice boundary dataset for the community atmosphere model. J. Climate, 21, 51455153.

Kalnay, E., and Coauthors, 1996: The NCEP/NCAR 40-Year Reanalysis Project. Bull. Amer. Meteor. Soc., 77, 437-471.

Key, R. M., and Coauthors, 2004: A global ocean carbon climatology: Results from Global Data Analysis Project (GLODAP). Global Biogeochem. Cycles, 18, GB4031, doi:10.1029/ $2004 \mathrm{~GB} 002247$.

Krishnamurthy, A., J. K. Moore, C. S. Zender, and C. Luo, 2007: Effects of atmospheric inorganic nitrogen deposition on ocean biogeochemistry. J. Geophys. Res., 112, G02019, doi:10.1029/ 2006JG000334.

,,-- N. Mahowald, C. Luo, S. Doney, K. Lindsay, and C. S. Zender, 2009: Impacts of increasing anthropogenic soluble iron and nitrogen deposition on ocean biogeochemistry. Global Biogeochem. Cycles, 23, GB3016, doi:10.1029/2008GB003440.

Lamarque, J.-F., and Coauthors, 2010: Historical (1850-2000) gridded anthropogenic and biomass burning emissions of reactive gases and aerosols: Methodology and application. Atmos. Chem. Phys., 10, 7017-7039, doi:10.5194/acp-10-70172010.

Landrum, L., M. M. Holland, D. P. Schneider, and E. Hunke, 2012: Antarctic sea ice climatology, variability, and late twentiethcentury change in CCSM4. J. Climate, 25, 4817-4838.

Large, W. G., and S. Yeager, 2009: The global climatology of an interannually varying air-sea flux data set. Climate Dyn., 33, 341-364, doi:10.1007/s00382-008-0441-3.

, J. C. McWilliams, and S. C. Doney, 1994: Oceanic vertical mixing: A review and a model with a nonlocal boundary layer parameterization. Rev. Geophys., 32, 363-403, doi:10.1029/ 94RG01872.

Lawrence, D. M., K. W. Oleson, M. G. Flanner, C. G. Fletcher, P. J. Lawrence, S. Levis, S. C. Swenson, and G. B. Bonan, 2012: The CCSM4 land simulation, 1850-2005: Assessment of surface climate and new capabilities. J. Climate, 25, 2240-2260.

Le Quéré, C., and Coauthors, 2009: Trends in the sources and sinks of carbon dioxide. Nat. Geosci., 2, 831-836, doi:10.1038/ ngeo689.

- T. Takahashi, E. T. Buitenhuis, C. Rödenbeck, and S. C. Sutherland, 2010: Impact of climate change and variability on the global oceanic sink of $\mathrm{CO}_{2}$. Global Biogeochem. Cycles, 24, GB4007, doi:10.1029/2009GB003599.

Lovenduski, N. S., N. Gruber, S. C. Doney, and I. D. Lima, 2007: Enhanced $\mathrm{CO}_{2}$ outgassing in the Southern Ocean from a positive phase of the southern annular mode. Global Biogeochem. Cycles, 21, GB2026, doi:10.1029/2006GB002900.

,-- , and -2008 : Toward a mechanistic understanding of the decadal trends in the Southern Ocean carbon sink. Global Biogeochem. Cycles, 22, GB3016, doi:10.1029/2007GB003139.

—, M. C. Long, P. R. Gent, and K. Lindsay, 2013: Multi-decadal trends in the advection and mixing of natural carbon in the Southern Ocean. Geophys. Res. Lett., 40, 139-142, doi:10.1029/ 2012GL054483.

Marshall, J., and T. Radko, 2003: Residual-mean solutions for the Antarctic Circumpolar Current and its associated overturning circulation. J. Phys. Oceanogr., 33, 2341-2354. 
Matsumoto, K., and N. Gruber, 2005: How accurate is the estimation of anthropogenic carbon in the ocean? An evaluation of the $\Delta \mathrm{C}^{*}$ method. Global Biogeochem. Cycles, 19, GB3014, doi:10.1029/2004GB002397.

McKinley, G. A., A. R. Fay, T. Takahashi, and N. Metzl, 2011: Convergence of atmospheric and North Atlantic carbon dioxide trends on multidecadal timescales. Nat. Geosci., 4, 606610, doi:10.1038/ngeo1193.

Metzl, N., 2009: Decadal increase of oceanic carbon dioxide in southern Indian Ocean surface waters (1991-2007). Deep-Sea Res. II, 56, 607-619, doi:10.1016/j.dsr2.2008.12.007.

Mikaloff Fletcher, S. E., and Coauthors, 2006: Inverse estimates of anthropogenic $\mathrm{CO}_{2}$ uptake, transport, and storage by the ocean. Global Biogeochem. Cycles, 20, GB2002, doi:10.1029/ 2005 GB002530.

— and sinks of natural $\mathrm{CO}_{2}$ and the implied oceanic carbon transport. Global Biogeochem. Cycles, 21, GB1010, doi:10.1029/ 2006GB002751.

Moore, J. K., and M. R. Abbott, 2000: Phytoplankton chlorophyll distributions and primary production in the Southern Ocean. J. Geophys. Res., 105 (C12), 28 709-28722.

- S. C. Doney, J. A. Kleypas, D. M. Glover, and I. Y. Fung, 2002: An intermediate complexity marine ecosystem model for the global domain. Deep-Sea Res. II, 49, 403-462, doi:10.1016/S0967-0645(01)00108-4.

, __ , and K. Lindsay, 2004: Upper ocean ecosystem dynamics and iron cycling in a global three-dimensional model. Global Biogeochem. Cycles, 18, GB4028, doi:10.1029/2004GB002220.

_ K. Lindsay, S. C. Doney, M. C. Long, and K. Misumi, 2013: Marine ecosystem dynamics and biogeochemical cycling in the Community Earth System Model [CESM1(BGC)]: Comparison of the 1990s with the 2090s under the RCP 4.5 and RCP 8.5 scenarios. J. Climate, in press.

Najjar, R., and J. Orr, 1998: Design of OCMIP-2 simulations of chlorofluorocarbons, the solubility pump and common biogeochemistry. IPSL, $19 \mathrm{pp}$. [Available online at http://ocmip5. ipsl.jussieu.fr/OCMIP/phase2/simulations/design.ps.]

Nakamura, T., T. Toyoda, Y. Ishikawa, and T. Awaji, 2006: Effects of tidal mixing at the Kuril Straits on North Pacific ventilation: Adjustment of the intermediate layer revealed from numerical experiments. J. Geophys. Res., 111, C04003, doi:10.1029/ 2005JC003142.

Neale, R. B., J. Richter, S. Park, P. H. Lauritzen, S. J. Vavrus, P. J. Rasch, and M. Zhang, 2013: The mean climate of the Community Atmosphere Model version 4 (CAM4) in forced SST and coupled experiments. J. Climate, 26, 5150-5168.

Park, G., and Coauthors, 2010: Variability of global net sea-air $\mathrm{CO}_{2}$ fluxes over the last three decades using empirical relationships. Tellus, 62B, 352-368, doi:10.1111/j.1600-0889.2010.00498.x.

Russell, J., R. Stouffer, and K. Dixon, 2006: Intercomparison of the Southern Ocean circulations in IPCC coupled model control simulations. J. Climate, 19, 4560-4575.

Sabine, C. L., and Coauthors, 2004: The oceanic sink for anthropogenic $\mathrm{CO}_{2}$. Science, 305, 367-371, doi:10.1126/science.1097403.
Sarmiento, J., and N. Gruber, 2006: Ocean Biogeochemical Dynamics. Princeton University Press, $526 \mathrm{pp}$.

Smith, R. D., and Coauthors, 2010: The Parallel Ocean Program (POP) reference manual. Los Alamos National Laboratory Tech. Rep. LAUR-10-01853, 140 pp.

Takahashi, T., R. Feely, R. Weiss, R. Wanninkhof, D. Chipman, S. Sutherland, and T. Takahashi, 1997: Global air-sea flux of $\mathrm{CO}_{2}$ : An estimate based on measurements of sea-air $p \mathrm{CO}_{2}$ difference. Proc. Natl. Acad. Sci. USA, 94, 8292-8299.

— , and Coauthors, 2002: Global sea-air $\mathrm{CO}_{2}$ flux based on climatological surface ocean $p \mathrm{CO}_{2}$, and seasonal biological and temperature effects. Deep-Sea Res. II, 49, 1601-1622, doi:10.1016/S0967-0645(02)00003-6.

— , and Coauthors, 2009: Climatological mean and decadal change in surface ocean $p \mathrm{CO}_{2}$, and net sea-air $\mathrm{CO}_{2}$ flux over the global oceans. Deep-Sea Res. II, 56, 554-577, doi:10.1016/ j.dsr2.2008.12.009.

Thomas, H., A. E. Friederike Prowe, I. D. Lima, S. C. Doney, R. Wanninkhof, R. J. Greatbatch, U. Schuster, and A. Corbière, 2008: Changes in the North Atlantic Oscillation influence $\mathrm{CO}_{2}$ uptake in the North Atlantic over the past 2 decades. Global Biogeochem. Cycles, 22, GB4027, doi:10.1029/ $2007 \mathrm{~GB} 003167$.

Thompson, D. W. J., and S. Solomon, 2002: Interpretation of recent Southern Hemisphere climate change. Science, 296, 895-899, doi:10.1126/science.1069270.

Thornton, P., and Coauthors, 2009: Carbon-nitrogen interactions regulate climate-carbon cycle feedbacks: Results from an atmosphere-ocean general circulation model. Biogeosciences, $\mathbf{6}$, 2099-2120, doi:10.5194/bg-6-2099-2009.

Toggweiler, J. R., and J. Russell, 2008: Ocean circulation in a warming climate. Nature, 451, 286-288, doi:10.1038/nature06590.

Trenberth, K. E., 1997: The definition of El Niño. Bull. Amer. Meteor. Soc., 78, 2771-2777.

Wang, G., and D. Schimel, 2003: Climate change, climate modes, and climate impacts. Annu. Rev. Environ. Resour., 28, 1-28, doi:10.1146/annurev.energy.28.050302.105444.

Wang, S., and J. K. Moore, 2012: Variability of primary production and air-sea $\mathrm{CO}_{2}$ flux in the Southern Ocean. Global Biogeochem. Cycles, 26, GB1008, doi:10.1029/2010GB003981.

,,-- F. W. Primeau, and S. Khatiwala, 2012: Simulation of anthropogenic $\mathrm{CO}_{2}$ uptake in the CCSM3.1 ocean circulationbiogeochemical model: Comparison with data-based estimates. Biogeosciences, 9, 1321-1336, doi:10.5194/bg-9-1321-2012.

Wanninkhof, R., 1992: Relationship between wind speed and gas exchange over the ocean. J. Geophys. Res., 97 (C5), 7373 7382.

Weijer, W., and Coauthors, 2012: The Southern Ocean and its climate in CCSM4. J. Climate, 25, 2652-2675.

Weiss, R. F., 1974: Carbon dioxide in seawater: The solubility of an ideal gas. Mar. Chem., 2, 203-215, doi:10.1016/ 0304-4203(74)90015-2.

- and B. Price, 1980: Nitrous oxide solubility in water and seawater. Mar. Chem., 8, 347-359, doi:10.1016/0304-4203(80)90024-9.

Zwiers, F. W., and H. von Storch, 1995: Taking serial correlation into account in tests of the mean. J. Climate, 8, 336-351. 